\title{
Geoheritage and Resilience of Dallol and the Northern Danakil Depression in Ethiopia
}

\author{
Viktor Vereb $^{1,2}$ (I) Benjamin van Wyk de Vries ${ }^{2} \cdot$ Miruts Hagos $^{3} \cdot$ Dávid Karátson $^{1}$
}

Received: 22 November 2019 / Accepted: 29 July 2020 / Published online: 26 September 2020

(C) The Author(s) 2020

\begin{abstract}
The Danakil Depression, located in the northern segment of the Afar rift, is a world-class example of active rifting and the birth of a new ocean. The unique, yet only partially interpreted geothermal system of Dallol in northern Danakil is currently receiving renewed attention by researchers and visitors despite its extreme climate since the recent improvements of infrastructure and the stabilisation of Ethio-Eritrean political relations. Previous studies focused on the general geological description, the economic exploitation of potash reserves and interpretation of the complex hydrothermal processes. Continuing monitoring of geothermal activity has not yet been carried out, and the valorisation of local geoheritage has not accompanied the increased interest of tourists. Here, we present a three-step study in order to demonstrate the unique geological environment and international geoheritage significance of Dallol and Danakil. A three-year-long remote sensing campaign has been done to provide information on improving the resilience of visitors through interpreted, monthly hazard maps, and on following up the changes of geothermal activity. Over the same time, the first geoheritage assessment of the region for 13 geosites was carried out along with a comparative analysis of three quantitative methods (to evaluate the scientific importance and the geotouristic development potential of the area). Finally, with the input of the assessment, a preliminary geoheritage management plan was created for practical consideration by stakeholders toward a geoconservation and geotourism development, as well as a resilience system of this peculiar area.
\end{abstract}

Keywords Ethiopia $\cdot$ Dallol $\cdot$ Geoheritage $\cdot$ Resilience $\cdot$ Geosite inventory $\cdot$ Monitoring

\section{Introduction}

Geologically active areas, such as volcanic domains are often powerful tourist attractions (Erfurt-Cooper 2011). When assessing such sites for geoheritage and geotourism, natural risks should be carefully considered. The 2019 tourist disaster at White Island, New Zealand emphasises that volcanoes and hydrothermal systems should only be visited with extreme caution, with a high degree of advanced planning.

Viktor Vereb

vereb.viktor.622@gmail.com

1 Department of Physical Geography, Faculty of Sciences, Eötvös Loránd University, Budapest, Hungary

2 Laboratoire Magmas et Volcans, Observatoire du Physique du Globe de Clermont, IRD, UMR6524-CNRS, Université Clermont Auvergne, Aubière, France

3 School of Earth Sciences, University of Mekelle, Mekelle, Ethiopia
In this paper, we take a holistic approach to geoheritage and geohazard resilience at Dallol, Ethiopia. In a three-step study, we start by identifying and monitoring hazards, then move on to inventorying and assessment of geosites, and finally bring both together to outline a preliminary management plan for the area, taking into account resilience to geohazards and the global importance of the geoheritage.

In the first part on monitoring, we present the geothermal activity at Dallol and the adjacent Black Mountain, where geoheritage features change frequently. A simple workflow of satellite image interpretation gives an overview of monthly activity patterns, from which a series of hazard maps have been made and published, which could be used to improve the resilience of visitors to the area by providing more up-todate information and increased awareness of risks.

Following this, we present the first preliminary geosite assessment of northern Danakil using three distinct methods, Vujičić et al. (2011), Brilha (2016) and Reynard et al. (2016), in order to assess their scientific importance in a quantitative manner and also to measure their touristic potential 
numerically. Comparison of the methods provided a broad summary of the diverse and varied considerations of geoheritage from three different viewpoints, based on numerous criteria.

Finally, combining the monitoring results and the geoheritage assessment, we propose a preliminary geoheritage management plan as a template that could be adopted and modified by local actors, to protect the site, protect the visitors and promote sustainable development of the area.

\section{The Global and Ethiopian Context of Geoheritage and Geohazards Resilience}

Geoheritage and geoconservation is a multi-disciplinary approach and a new domain in geosciences, which has been evolving constantly, predominantly over the last three decades, but with early initiatives traceable back to the nineteenth century (Brocx and Semenyuk 2007; Burek and Prosser 2008; Reynard and Brilha 2018). International recognition was widely fostered by the formation of the geoparks movement (Zouros 2004; Jones 2008; UNESCO-IGGP 2015), and the recognition of abiotic elements in nature protection by the International Union for Conservation of Nature (Dudley 2008). However, the domain is still lagging behind biodiversity and cultural heritage management, as noted by Brilha (2018), and the terms used in geoheritage are scarcely mentioned in key documents of the United Nations and their associated organisations and programmes.

Resilience is the ability of a system, community or society that is exposed to hazards to resist, absorb, accommodate to and recover from the effects of a hazard in a timely and efficient manner, including through the preservation and restoration of its essential basic structures and functions (UNISDR 2009). The role of geoheritage in the improvement of resilience through inclusion into risk management and raising awareness through educational activities was addressed by the Shimbara Declaration (GGN 2012) and is the subject of several papers (such as Giardino et al. 2014; Nakada 2018; Gizzi et al. 2019).

Areas of outstanding geoheritage are often exposed to natural hazards, and can be highly vulnerable both through their intrinsic values and through visitors to the area. Human activities such as tourism or exploitation of resources (even in a sustainable manner) are also a hazard to geoheritage areas. The significant potential of risks, through the multiplied factors of hazard and vulnerability (Scaini et al. 2014), call for the integration of risk management into geoconservation strategies.

In Africa, some issues of geodiversity have been covered for key sites of geosciences and for the potential role of geotourism under sustainable development and ecotourism (e.g. Schneider and Schneider 2005; Cumbe 2007; Asrat et al. 2012; Errami et al. 2013; Ngwira 2015; Thomas and Asrat 2018). Nonetheless, examples of dedicated geoconservation practices in terms of legislation or other effective forms are still limited. As of 2020, only two UNESCO Global Geoparks (UGGp) exist in the continent, the Ngorongogo Lengai UGGp in Tanzania and the M'Goun UGGp in Morocco (GGN 2020). In terms of natural World Heritage sites, only nine sites are inscribed under criterion (viii) related to Earth's history and physiographic landforms. A further 25 are inscribed under criterion (vii) of 'superlative natural phenomena or areas of exceptional natural beauty and aesthetic importance', some of them containing sites of geoheritage relevance (WDPA 2020).

Ethiopia has one of the highest numbers of World Heritage Sites in Africa, with nine examples (Fig. 1). None of them is directly inscribed under criterion (viii), but Simien National Park was partially enlisted for its natural beauty under criterion (vii) (Mauerhofer et al. 2017). Several cultural designations also have an associated geoheritage importance such as the paleontological values for hominids of the Lower Valley of Awash and the Lower Valley of Omo, or the heritage stone significance of the Rock-hewn churches of Lalibela or Aksum (Renzulli et al. 2011; Hagos et al. 2017; Megerssa et al. 2019). An overview of Ethiopian geodiversity has been given by Williams (2016) and Asrat (2018), but no national level geoconservation project or geosite inventorying project has been implemented as yet. So far, the geomorphosite inventory of the Simien Mountains (Mauerhofer et al. 2017), the geosite inventory of the Butajira Volcanic Field (Megerssa et al. 2019) and the geo-trekking guide of Dogu'a Tembien (Nyssen et al. 2019) are the sole examples of dedicated and detailed geoheritage assessment processes in Ethiopia.

The scientific importance of Mt. Dallol and its complex and still not fully understood geothermal system is limited to a handful of studies (e.g. Holwerda and Hutchinson, Warren 2015a; Franzson et al. 2015; Cavalazzi et al. 2019; López-García et al. 2020), while its aesthetic values attract a growing number of visitors every year (ARCTB 2019, Fig. 2). The active geothermal manifestations of the area, such as acidic ponds or fumaroles, are probably the most important geological features, and they are a primary interest for (geo)tourism and research despite being highly hazardous phenomena with extreme temperatures and $\mathrm{pH}$. The lack of any protection infrastructure for the geoheritage values and for the visitors results in a low level of resilience. This could potentially lead to dangerous scenarios, where increasing visitor numbers is not accompanied by increased risk awareness and preparation. Hence, the need to identify potential risks alongside the geoheritage and address them through management strategies. 


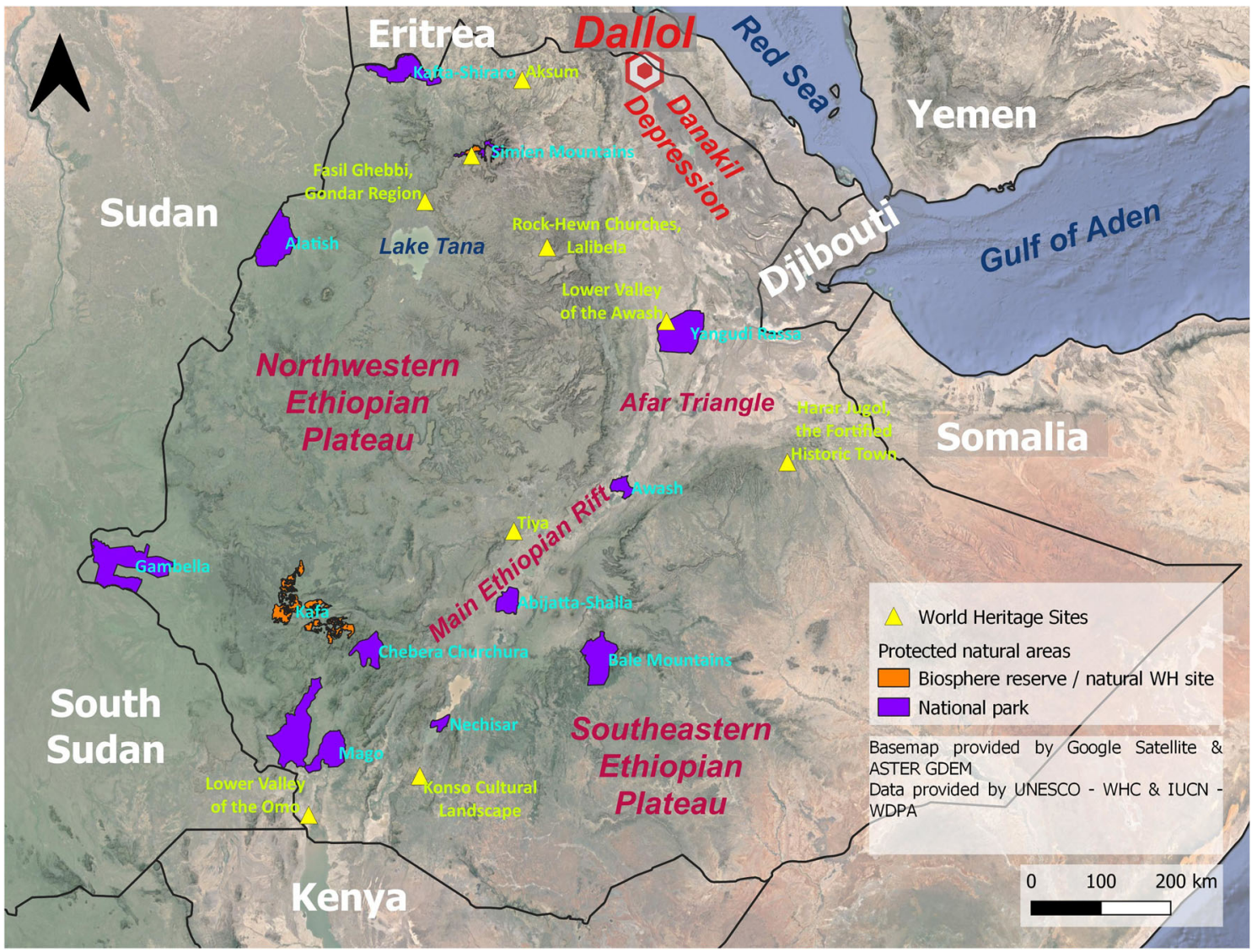

Fig. 1 The Ethiopian Protected Area System of national parks and World Heritage sites (Source: WHC, WDPA (2020). Basemap: Google Satellite)

\section{Geology and Geography of the Danakil Depression and Dallol}

\section{The Danakil Depression}

Mount Dallol is situated in the Danakil Depression, which is part of the East African Rift System, spanning from Mozambique to the Arabian Peninsula (Rogers 2006; Darrah et al. 2013).

The Afar Depression, also known as the Afar Triangle, is a world-renowned example of continental rifting, and

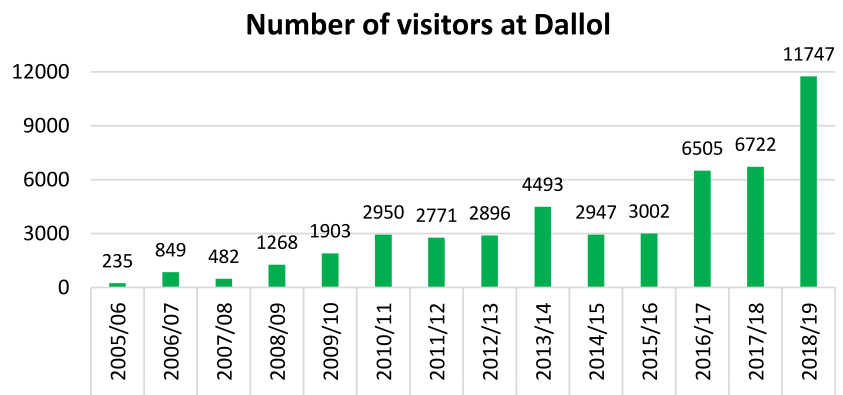

19981999200020012002200320042005200620072008200920102011 Ethiopian year (horizontal) and Gregorian year (vertical)

Fig. 2 Visitors statistics of Dallol (ARCTB 2019) the inception of oceanic crust formation, forming a subaerial triple junction at the intersection of the Gulf of Aden, the Red Sea and the Main Ethiopian Rift (Barberi et al. 1970; Tazieff et al. 1972; Makris and Ginzburg 1987; Rogers 2006).

The Danakil Depression (Fig. 3) itself could be considered the northern section of the Afar Depression, covering a roughly triangular shaped area of $50,000 \mathrm{~km}^{2}$, flanked by the Great Ethiopian Escarpment (Balakia Mountains) to the West, the Danakil Alps to the East and Lake Afrera to the South (Lupi 2009; Nobile et al. 2012).

Rifting in the Afar region started during the Miocene, about $30 \mathrm{Ma}$, and is ongoing with a spreading rate of 7$20 \mathrm{~mm} /$ year (Nobile et al. 2012). Active volcanism and hydrothermal activity take place along a number of NNWSSE orientated axial volcanic ranges, the most prominent of which is the Erta Ale Range (Barberi et al. 1970; Nobile et al. 2012; Hagos et al. 2016). Predominantly basaltic in composition, the range comprises several volcanoes with Holocene activity, such as Alu-Dalafilla. The best known of them is the eponymous Erta Ale, one of the rare examples of an active lava lake on Earth (Fig. 3).

The northern half of the Danakil Depression is dominated by a salt pan, also referred to as the Dallol salt flat 


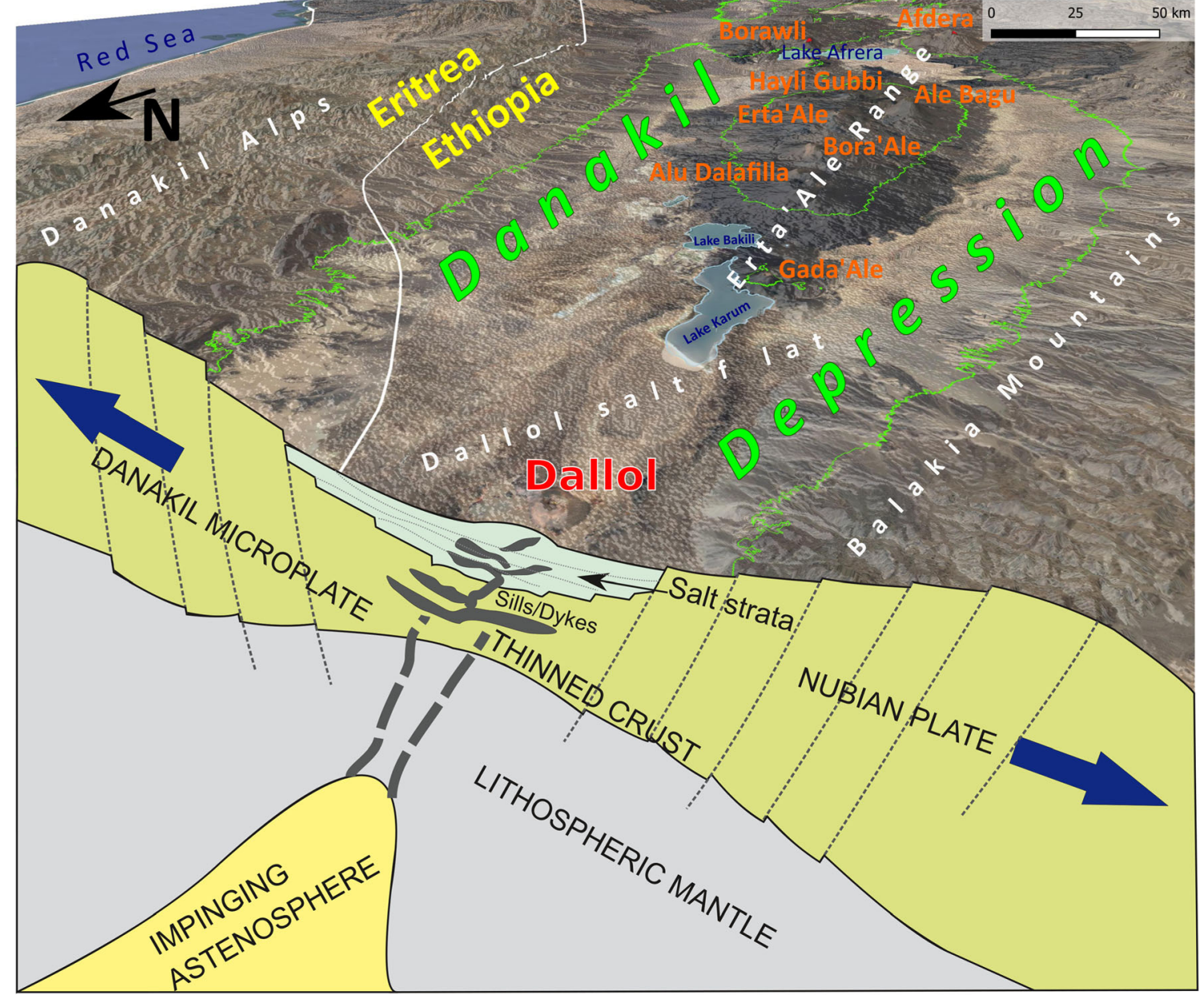

Fig. 3 Overview oblique image and simplified tectonic sketch cross section of the Danakil Depression. Vertical extent is distorted and not to scale. The green line marks the current sea level. (Basemap: Google Satellite, DEM: SRTM - de Ferranti)

(Warren 2015a), forming the deepest part of the depression which reaches $120 \mathrm{~m}$ below sea level. The basin is infilled with a series of Quaternary evaporites that may underlie the entire depression and is covered by volcanic successions in the southern part (Erta Ale Range). Geophysical surveys and drilling have mostly been carried out in the NW section, close to Mount Dallol, where economically exploitable potash deposits are located (Holwerda and Hutchinson 1968). A succession of evaporites of at least $970 \mathrm{~m}$ thick is made up of two, thick units of halite, the Lower and Upper Rock Salt Formation, separated by the potash-bearing Houston Formation, as well as sequences of kainitite, carnallite, bishofite and sylvinite. Their depth ranges from 38 to $190 \mathrm{~m}$ near Dallol to 683-930 m to the east (Warren 2015b).

Marine seepage into the current salt flat is prevented by a shallow, volcano-tectonic barrier in the north, but deposition of halite and gypsum still takes place at Lake Assale (or Lake Karum). Periodical rainfall on the Western Escarpment can cause flash floods, running down wadis to flood certain parts of the salt plain
(Holwerda and Hutchinson 1968). The periodic inundation is followed by rapid evaporation, creating a new crust of halite and mud which often shows a typical hexagonal drying-up structure (Goudie 1989).

\section{Mount Dallol and Black Mountain}

Mount Dallol itself is a complex, uplifted, halo-volcanic dome structure (Franzson et al. 2015; López-García et al. 2020), rising $60 \mathrm{~m}$ above the surrounding salt flat. Mount Dallol has been regularly interpreted as a volcano (Franzson et al. 2015; Warren 2015a) due to its crater-like central structure, the geothermal activity and the resulting landforms that resemble volcanic features (the latter being interpreted as salt hornitos and maars). Further evidence comes from a positive gravity anomaly and magnetic measurements indicating intrusions, and a phreatic explosion at the nearby Black Mountain in 1926. Although a dike intrusion from a magma reservoir from below Dallol has been suggested (Nobile et al. 2012), and the updoming of the salt strata and the presence of a heat source of the hydrothermal system imply a connection to 
dykes or a magma chamber, probably via sills (e.g. Holwerda and Hutchinson 1968; Franzson et al. 2015), only scattered presence of volcanic products are reported (Hagos et al. 2016). López-García et al. (2020) consider Dallol as a (proto)volcano, and Franzson et al. (2015) as a magmatically driven hydrothermal system, but a general consensus about the exact evolution and framework of the Dallol dome has not been reached yet.

The focal structure of Dallol is a 1.4-km-wide bowl, surrounded by a rim $20 \mathrm{~m}$ higher than the deepest part of the bowl. Holwerda and Hutchinson (1968) interpreted it as a collapse crater, but according to Franzson et al. (2015), the rims do not show evidence of steep faulting; therefore, the bowl structure might have been formed by the gentle flexing of salt strata, as there is a ring of fractures (Franzson et al. 2015) The N-NW floor is generally flat, and the salt layers suggest ephemeral lake formation (Franzson et al. 2015). The central to southern part is dominated by a black dome structure and the iconic, constantly changing structures of geothermal ponds (Fig. 4).

Franzson et al. (2015), following Holwerda and Hutchinson (1968), described three typical structures that are present in active or inactive form at Dallol: pillars, circular manifestations and acid lakes (Fig. 4).
- Pillars can be several metres high and wide, often found in groups, and are most likely generated by boiling upflows, where halide precipitates at the top of the structure.

- Circular manifestations range from several metres to a hundred metres in diameter, also controlled by intense upflows and deposition of halides in circular or semicircular forms.

- Acid lakes are probably controlled by the mixture of groundwater and geothermal upflows, creating small ponds with extremely low $\mathrm{pH}$ (less than 1). Their extent and water level could change frequently, and the drastic colour changes from yellow to green to red might be interpreted as oxidation related to water table changes (Franzson et al. 2015).

López-García et al. (2020) suggested an evolutionary pattern of geothermal features, from chimneys and pillars to rounded flat-top geyser fields with lateral terraced ponds (these ponds could be the acid lakes of Franzson et al. 2015) that finally become inactive with the lowering of the water table level.

The Black Mountain, just south-southwest of Dallol, is an area of salt extrusions, geothermal manifestations and brine upflows (Fig. 4). The feature that gives its name to the site is a
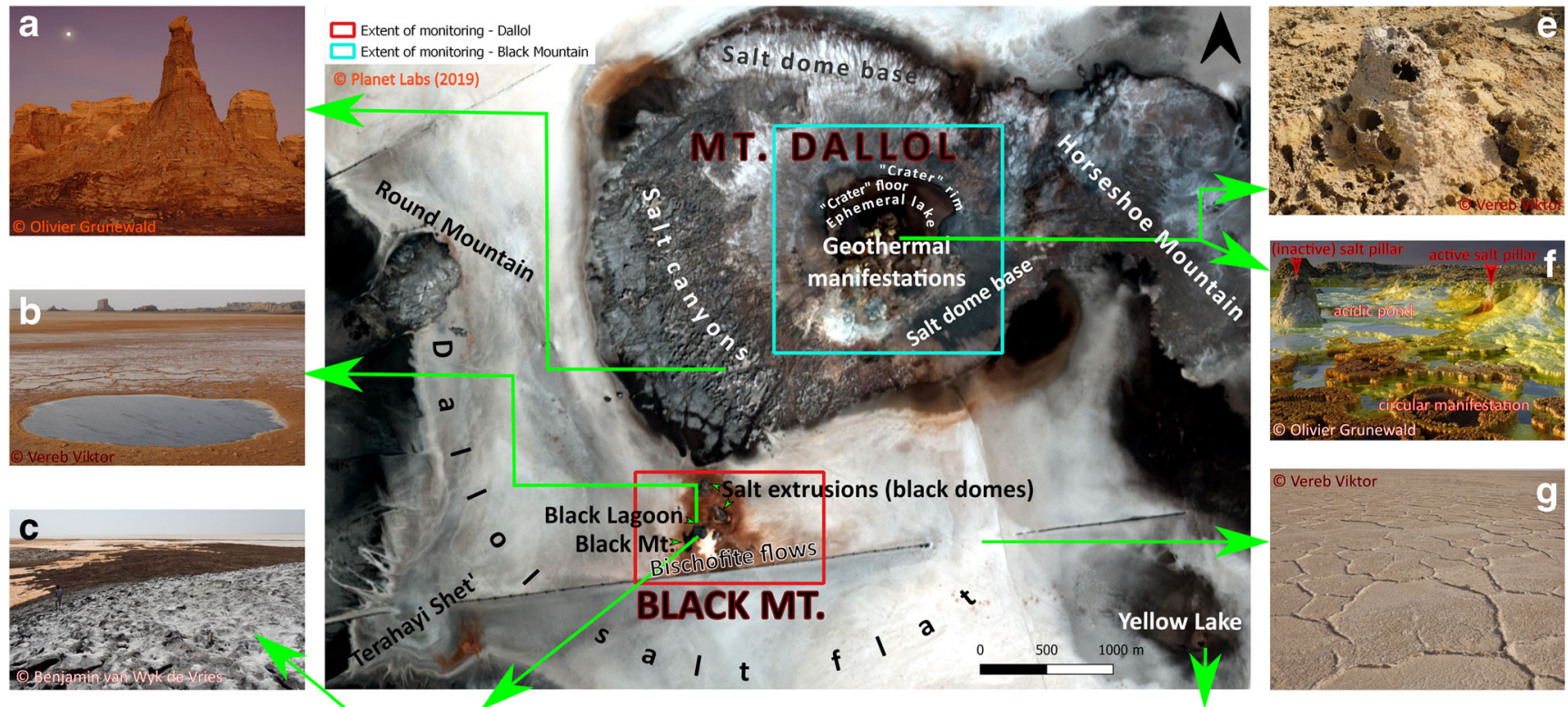

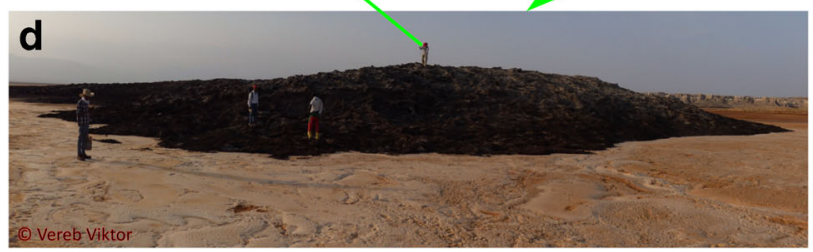

Fig. 4 Physiographical features of Dallol. a Salt pinnacles of the SW salt canyon area. b The super-saline Black Lagoon, site of the 1926 phreatic explosion. $\mathbf{c}$ Blocks of halite-mud mixture on the top of Black Mountain. d Black Mountain, the name bearing black dome, surrounded by a surface

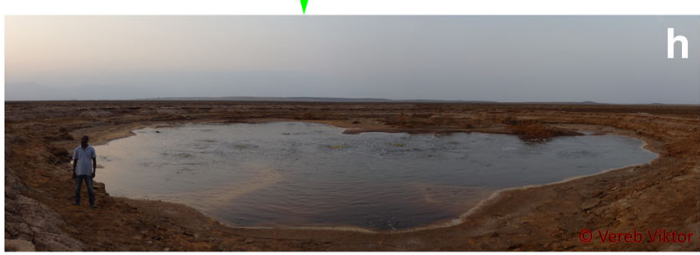

of bischofite flows. e Inactive fumarole. f Principal geothermal features of the central crater area of Dallol: salt pillars, circular manifestations and acidic ponds. g Hexagonal salt surface near Dallol. $\mathbf{h}$ The brine pool of Yellow Lake 
black dome, created by highly viscous salt upflows, articulated by hexagonal fractures and degassing pipes. It acquires its black colour from the abundant haematite in the halides (Franzson et al. 2015). The central elongated black dome is $200 \mathrm{~m}$ long and generally $30 \mathrm{~m}$ wide. It has smaller vertical extrusions to the north-northeast. Just to the north of the dome is a super-saline, hot $\left(\sim 70^{\circ} \mathrm{C}\right)$ lake called the Black Lagoon or Black Pool, which is interpreted as occupying the site of a 1926 phreatic explosion (Holwerda and Hutchinson 1968). To the S-SE of the central black dome is a constantly changing area with regular super-saline outflows which precipitate bischofite, a magnesium-chloride mineral (Franzson et al. 2015; López-García et al. 2020).

The majority of geothermal features are concentrated at Dallol and Black Mountain, but there is a third, smaller manifestation at the Yellow Lake or Brine Pool, $3.5 \mathrm{~km} \mathrm{SE}$ of Mount Dallol (Holwerda and Hutchinson 1968). The Terahayi Shet', a 100-m-wide circular crater was possibly also generated by a geothermal system, and creates saline mudflows of unknown frequency W-SW from Dallol, close to the bajadas (Franzson et al. 2015).

The S-SW segment of Mount Dallol and the area N-NE from the central crater are dominated by a labyrinth of salt canyons and a series of erosional pinnacles, showing salt cyclothems of halite, gypsum and clay (Holwerda and Hutchinson 1968). Vertically dipping, kilometre-long salt dikes are also observable in the W-SW segment of Dallol, forming a series of ridges and depressions, and include rare altered basalts (Holwerda and Hutchinson 1968). These dykes have been partially mapped by Tibaldi et al. (2020) using drone images in Virtual Reality, and show several generations of intrusions. West of the Dallol salt canyons, there is a second dome structure called Round Mountain and to the east of Dallol is Horseshoe Mountain (predominantly made up of reddish halite), but these features have not yet been studied in detail (Holwerda and Hutchinson 1968).

\section{History of Resource Exploitation and Research}

In spite of the extreme climate of the region, where daily temperatures regularly exceed $40{ }^{\circ} \mathrm{C}$ and the precipitation remains well below $200 \mathrm{~mm}$ per year, the Danakil Depression is inhabited, in part due to its economic potential. The annually formed salt layers have been extracted by the local Afari people and the highlander Tigrinyas for centuries by traditional methods: quarrying with sticks and axes, carving the standardised, rectangular tiles of 'ganfur' and 'ghelao' (ca. 4 and $8 \mathrm{~kg}$ ), and transporting them with camels and donkeys to Berhale in the Great Escarpment, and further west to Mekelle, the regional centre and ancient capital (Warren 2015a).

From the second half of the nineteenth century, Italy touched on the Danakil Depression through a number of mostly unsuccessful expeditions and a colonisation attempts, which only succeeded along the Red Sea shoreline and the northern segment of Danakil, resulting in the colony of Italian Eritrea. The majority of the depression, including Dallol, remained under the dominance of the Empire of Ethiopia, although European economic interest continued. From 1906, the Italian firm of Compagnia Mineraria Coloniale started the extraction of potash at Black Mountain, first transporting it by camel and then along a newly constructed narrow-gauge railway from Dallol to the port of Mersa Fatma (Holwerda and Hutchinson 1968; Warren 2015a). Following some intense mining during the First World War, potash extraction ceased due to reduced demand and political tensions between Ethiopia and Italian Eritrea. After the Second World War, the railway was dismantled leaving no trace, and the potash concession was handed over to the Dallol Potash, Magnesium and Sulphur Mines Co. (Holwerda and Hutchinson 1968).

After 1954, the Ralph M. Parsons Company took over the concession and carried out the first systematic scientific description of the area to prepare for industrial potash extraction. They orchestrated the geological and topographical mapping of the area and the magnetic geophysical surveys, and more than 300 drill holes were drilled. The scientific paper of Holwerda and Hutchinson (1968), still the most detailed reconnaissance study of the region, was based on the industrial reports of this period. During a 9-year campaign, the Musley Deposit, a commercial sylvanite-bearing ore reserve was discovered, and preparations for industrial extraction were started. But after encountering numerous flooding events in the mine works, the company ceased its operation in 1968, leaving behind their mining camp (Fig. 5), which is currently a ghost town and industrial heritage site at Dallol (Warren 2015a).

Following the concession period of Parsons Inc., a number of companies were awarded the concession rights (e.g. Salzdetfuhrt AG, Hydro Agri International, BHP Billiton),

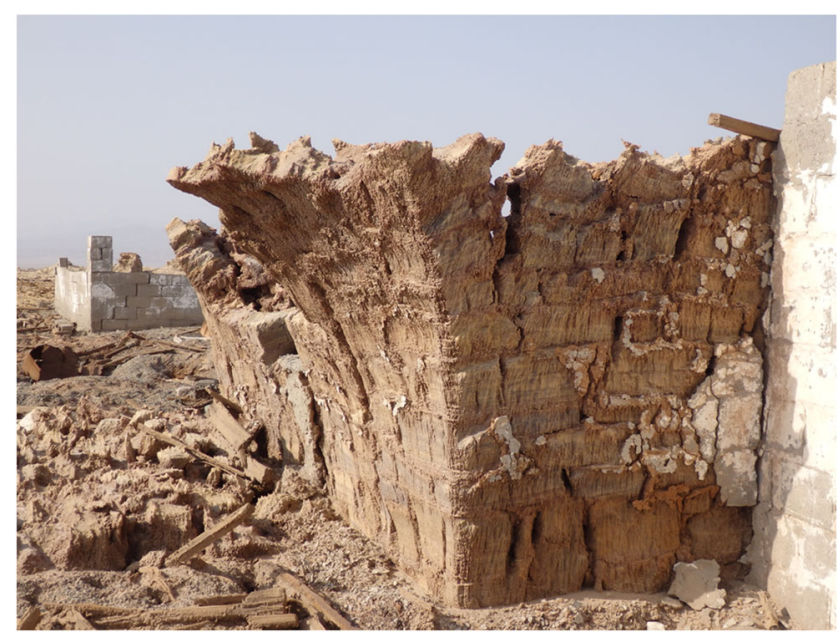

Fig. 5 Remains of the Parsons Mining Camp made from blocks of layered Dallol salt, now slowly falling apart and inclining. Note the straight concrete block building in the background as a contrast 
but operations were generally restricted to exploration work and re-interpretation of Parsons' studies (Warren 2015a). Industrial-scale extraction of materials at Dallol, and more widely in Danakil, was also significantly curtailed by socioeconomic problems and political turbulence affecting Ethiopia, such as the abolition of the Empire, the rule of the 'Derg' (Provisional Military Government of Socialist Ethiopia), the independence of Eritrea, and the constant clashes between Afari revolutionary movements and the state authorities of Ethiopia and Eritrea. Since 2015, large-scale exploration has returned through the work of Allana Potash Corp. and Yara Dallol Potash Project, and their data is being used again by scientists (Bastow et al. 2018).

Climatic extremes, political tensions and isolation in terms of infrastructure mean that the Danakil remains a seldom visited location. Moreover, despite the importance of geological processes and the economic resources of potash and halite, the number of research studies on Dallol and Danakil is still limited to a few key articles, e.g. Holwerda and Hutchinson (1968), Barberi et al. (1970), Tazieff et al. (1972), Carniel et al. (2010), Gebresilassie et al. (2011), Franzson et al. (2015), Belilla et al. (2019), Cavalazzi et al. (2019), Gómez et al. (2019) and López-García et al. (2020).

Permanently installed instruments and facilities for long-term monitoring of seismicity, gas and water chemistry or thermal changes, are completely missing at Dallol, and the studies above have relied on limited field excursions and subsidiary reports of economic geological reconnaissance.

\section{Remote Sensing Monitoring of Geothermal Activity and Landscape Changes}

Basic monitoring of the Dallol geothermal activity and landscape changes using satellite images was prompted by the fact that in situ monitoring facilities were not available as of 2019, and sporadic field-reconnaissance missions and measurements can only give a partial, extrapolated overview of longterm processes and changes. The growing number of visitors and their potential vulnerability, the economic importance of Dallol and the adjacent potash concession zones all call for hazard and risk assessment and monitoring. Therefore, a simple monthly monitoring process was created, giving a visual overview of changes and hazards for visitors and functioning as an input for further quantitative description of activity patterns of geothermal manifestations and bischofite upflows.

\section{Monitoring Methodology}

Ultra-high-resolution ( $3 \mathrm{~m}$ ) RapidEye satellite images were used in order to delineate the distinctive geological and geomorphological features and their areal changes, provided by
Planet Labs Inc. (2020). From the 4-band spectral dataset, only visible wavelengths were used. A monthly interval was chosen based on the supposed and observed rate of changes, the availability of ideal coverage and the required processing time. The availability of cloud-free coverage (to avoid similar reflectance values of salt and cloud pixels, and the eclipse of features) and the orbit of the satellite through Dallol meant that the intervals used varied slightly, but generally, the first day of each month was used.

A semi-automated workflow was created (Fig. 6), where manual intervention is restricted to data cleaning and supervision. The workflow was executed separately for Black Mountain and the central crater area of Dallol in order to minimise coverage of areas with little, slow or no change (e.g. salt flats, salt canyons) outside the geothermal areas. The input satellite images were classified by RGB pixel values with ENVI, with the supervised, maximum likelihood classification method of the software. Generally, 7-10 classes were delineated for Black Mountain and 10-15 for Dallol, with at least 3 training sites per class. The accuracy of pixel classification was generally around $70-80 \%$ (classified categories versus the extent of expected classes and features); therefore, purging or rectification of data was required.

Further phases of the workflow were carried out in QGIS (QGIS Development Team 2020), using the vector output of classification from ENVI. Cleaning covered the removal of artefacts (purging), the merging or division of classes and adding new features if needed. Final names of geological and geomorphological units (e.g. bischofite

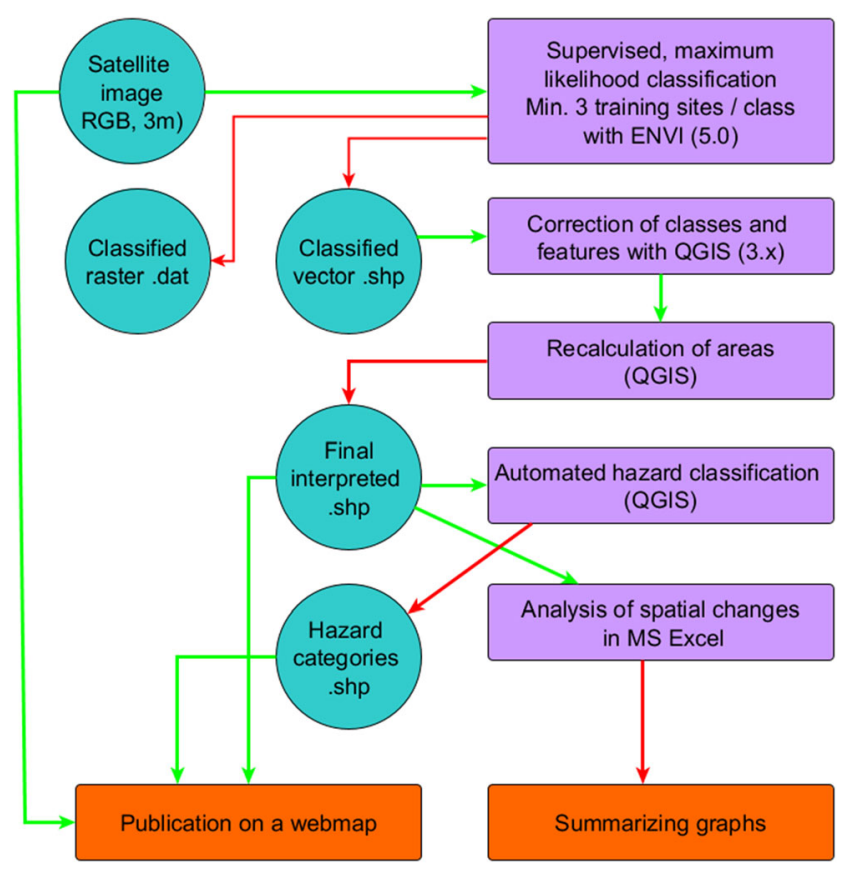

Fig. 6 Workflow of the remote sensing monitoring, showing the steps from data to graphical outputs 
flows) were assigned at this point, with the classification using a provisional naming protocol. Areas of each feature were also recalculated, as they could change significantly from the original classification values during the purging. Finally, a new symbology was also applied to each month.

The principal output of the workflow was the interpretation of the extent of geomorphological and geological units (Fig. 7). The workflow functions as a visual monitoring tool for areal changes of the geothermal manifestations (active and inactive ponds, bischofite flows) month-by-month, allowing the area of each feature to be compared numerically as well. It also operates as an input for hazard assessment. Based on reports about the units (especially from Holwerda and Hutchinson 1968 and Franzson et al. 2015) and our reconnaissance field trips of 2017 and 2019, each feature could be associated with a hazard value according to the stability of its material, the characteristic $\mathrm{pH}$ value and temperature as reported by previous studies such as Franzson et al. (2015). A five-level scale exposure from very low to very high level of hazard was used, and each unit was classified into these categories (Table 1). An automated workflow was created in QGIS with the Graphical Modeler to assign the hazard values to each feature. For high and very high (levels 4 and 5) categories, safety buffer zones of 5 and $15 \mathrm{~m}$ were also calculated in order to delineate a potential admissible distance for visitors (Fig. 7).

Since the start of monitoring in January 2017, nearly 3 years of dataset have been collected. The extraction of the areal extent of each geothermal feature by month allows a quantitative overview of changes and an initial idea about activity patterns. However, care should be taken extrapolating this, and several more years of consistent monitoring are required for a long-term baseline. These should be validated with regular field observation. It is beyond the scope of this paper to give a detailed overview of processes and landforms, and we focus on (i) the description of observations that are visible on the satellite images, (ii) their interpretation, and (iii) establishing a framework for further observations.

The accuracy of the automated classification was significantly improved with numerous human validation iterations, but this could not match field observations. For example, features smaller than 0.1 ha were omitted by the classification process, and in case of Dallol, several active, but isolated geothermal ponds might not reach this areal extent. This was the primary reason to have broad zones in the classification (e.g. active, inactive, active/inactive transition, where an indeterminable mosaic of small active and inactive features is observable) instead of standalone features of acidic ponds, circular manifestations, etc., so as to reduce information loss during classification and interpretation.

For the bischofite flows, any appearance of a new feature or continuing existence of a previous generation was determined by human supervision, as the genetic link had to be examined month-by-month, comparing possible alteration (resulting in a colour change), further growth of a previous feature or appearance of a new one. The different illumination of the surface by the sun or small quality differences in the monthly datasets might result in a colour (reflectance value) difference between the same type of geological features at different time periods, which underlines the importance of manual rectification.
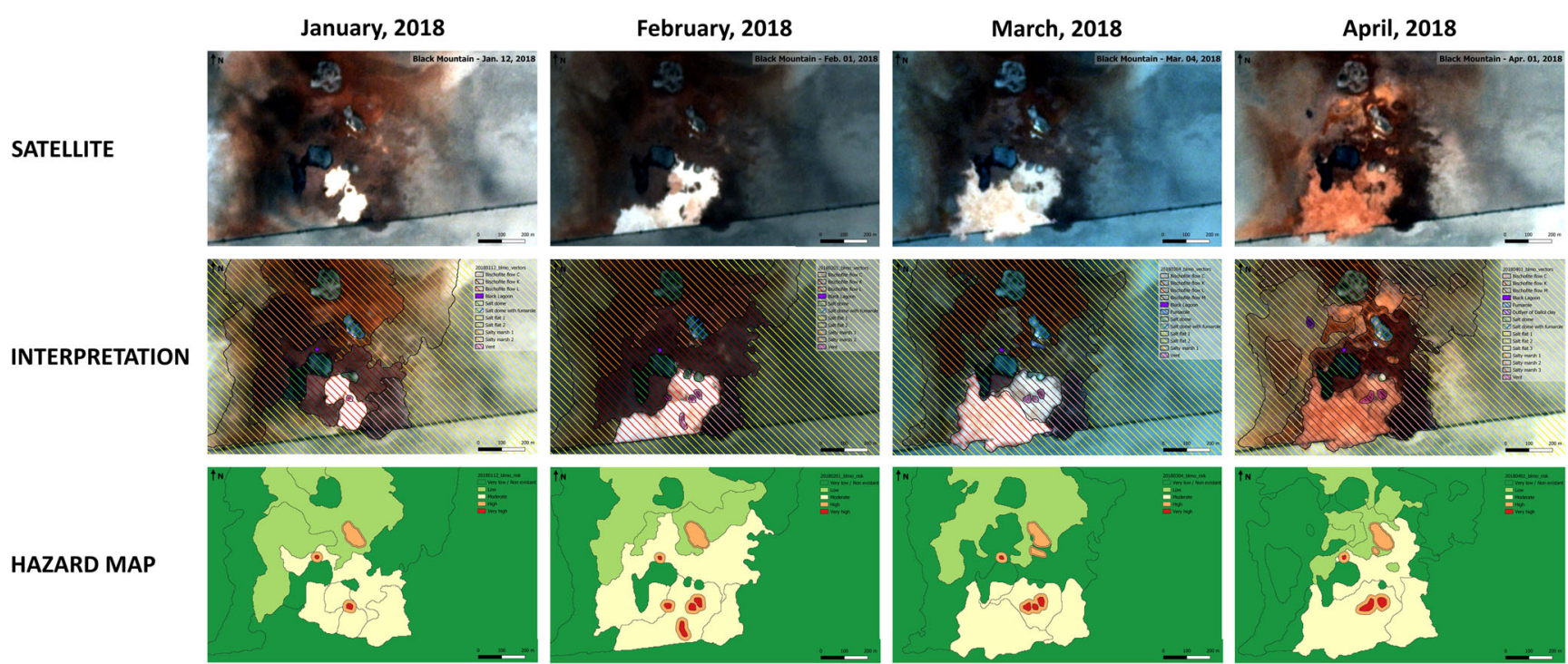

Fig. 7 An example from the monitoring dataset at Black Mountain, January-April, 2018. Note the dynamic growth of bischofite flow ' $\mathrm{K}$ ' in January and February, the appearance of a new flow ('L') in March,

and the alteration of previous ones in April, without the appearance of a new generation. The patterns of salt flats also change slightly month-bymonth, according to wind erosion, or even by possible periodic floods 


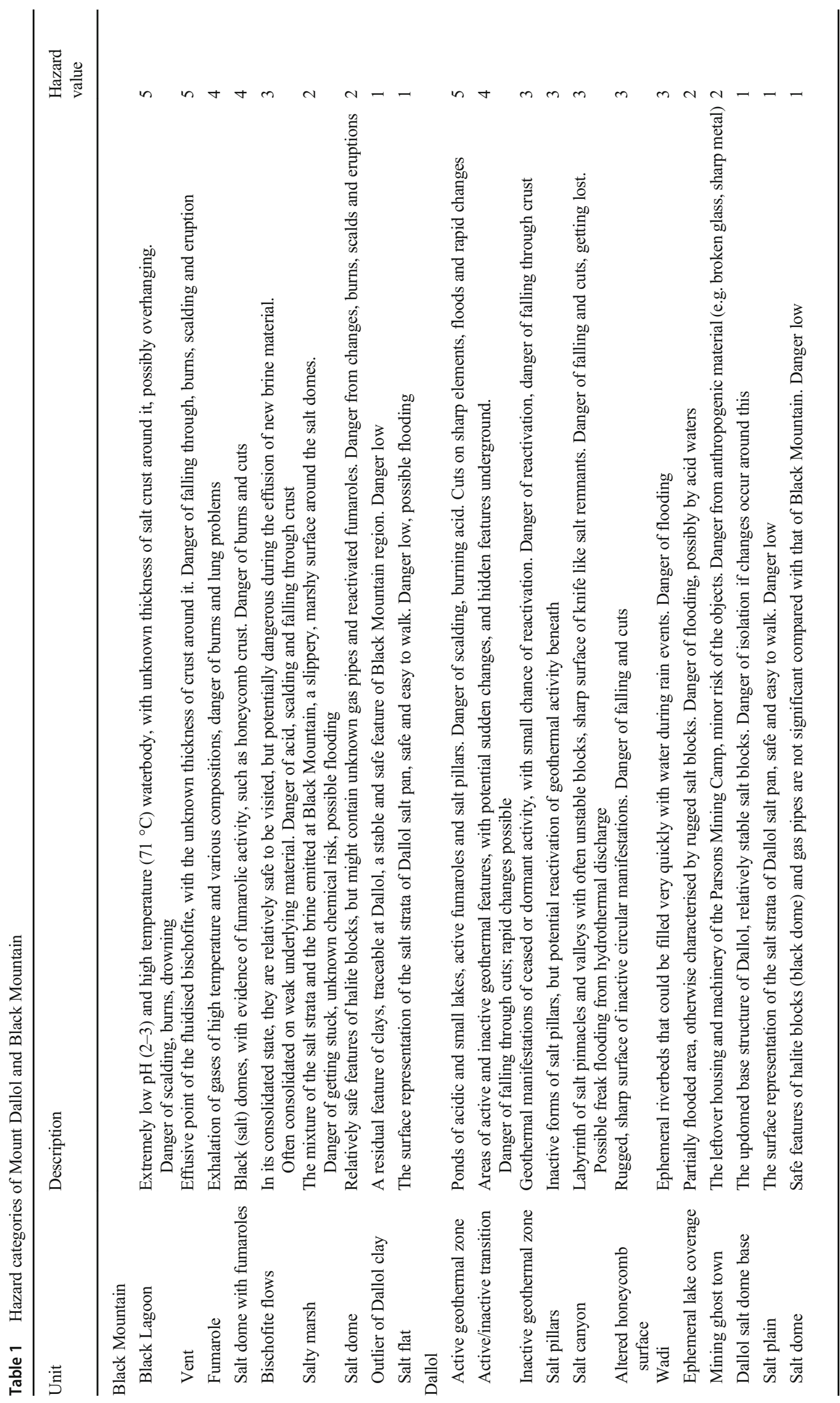




\section{Observations - Results}

\section{Monitoring of Mount Dallol}

Changes in activity in the central geothermal zone of Dallol are summarised in Fig. 8. A general decline of the areal extent of active geothermal zones is clearly visible: from the 15 23 ha in the first months of 2017, there is an overall decrease of 1-5 ha. The shrinkage was connected with an increase in inactive areas and accompanied by a smaller growth in transitional zones. Both zones show a significant variability month-by-month, and there might be true changes or possible mismatching with units of similar reflectance. For example, the brownish shade of inactive areas is similar to the reflectance values of the ephemeral lake coverage of the central crater. Also the active and inactive transitional areas might be classified differently by the automated method from month to month, due to the reflectance value changes in images.

Besides the general decline of active features, a slight seasonal pattern is also observable in Fig. 8. Winter and spring months (December to June) show a limited increase in activity (i.e. active, active/inactive transition zones) compared with the values of the summer to autumn period (July-November). This periodicity might be related to the seasonal water supply. Although water is thought to be largely provided by groundwater reservoirs (Franzson et al. 2015), periodic rain events might help reactivate some acidic ponds through shallow water supply to the hydrothermal system. A longer time series of data along with a comparison with meteorological data is required to confirm this hypothesis.

\section{Monitoring of Black Mountain}

Monitoring of geothermal activity at Black Mountain has focused on the SE area of bischofite flows. The historical continuity of brine upflows is well-known (Holwerda and
Huthchinson 1968; Franzson et al. 2015; López-García et al. 2020), but the volumes and evolution of the geothermal features have not been described. The time span of our monthly monitoring means that some upflow events might be missed, but in general, this interval was suitable to follow the evolution of the features from their appearance through to alteration, and subsequent coverage by new events.

From the start of the measurements, 34 flow events with various durations, magnitudes and surface coverage have been identified (up to November 2019). These are marked with alphabetic characters from $\mathrm{A}$ to $\mathrm{Z}$, and then continuing with AA, etc. (Fig. 9). Genetic connection of flow features on two subsequent satellite images were identified by the comparison of reflectance values and morphology, taking into consideration possible alteration marked by colour changes. Colour changes can be explained by rainfall and the deliquification of potash-related minerals, such as cainite or sylvinite (Holwerda and Hutchinson 1968). In the field, we actually observed that the surface of bischofite flows was also stripped by the wind.

At least one new feature appeared each month, but in several months (e.g. March 2017, August 2018), two separate flows appeared following different paths, and their colours indicated two distinct effusion episodes. There were only 7 months when no new unit appeared (June 2017, September and November 2018, February, April, June, August 2019), but it does not necessarily mean inactivity, only that the pre-existing flows continued to grow (e.g. flow ' $\mathrm{K}$ ' between October and November 2017).

From this image analysis, we see that a solidified surface exists for 3 months on average (Fig. 10); then it is covered up by a new flow, or its material is altered to brown, dissolved or eroded. One of the rare exceptions was flow ' $\mathrm{C}$ ' that we were able to follow in a highly altered form for 18 months. Having flowed in a SE direction, spilling through the rampart south of

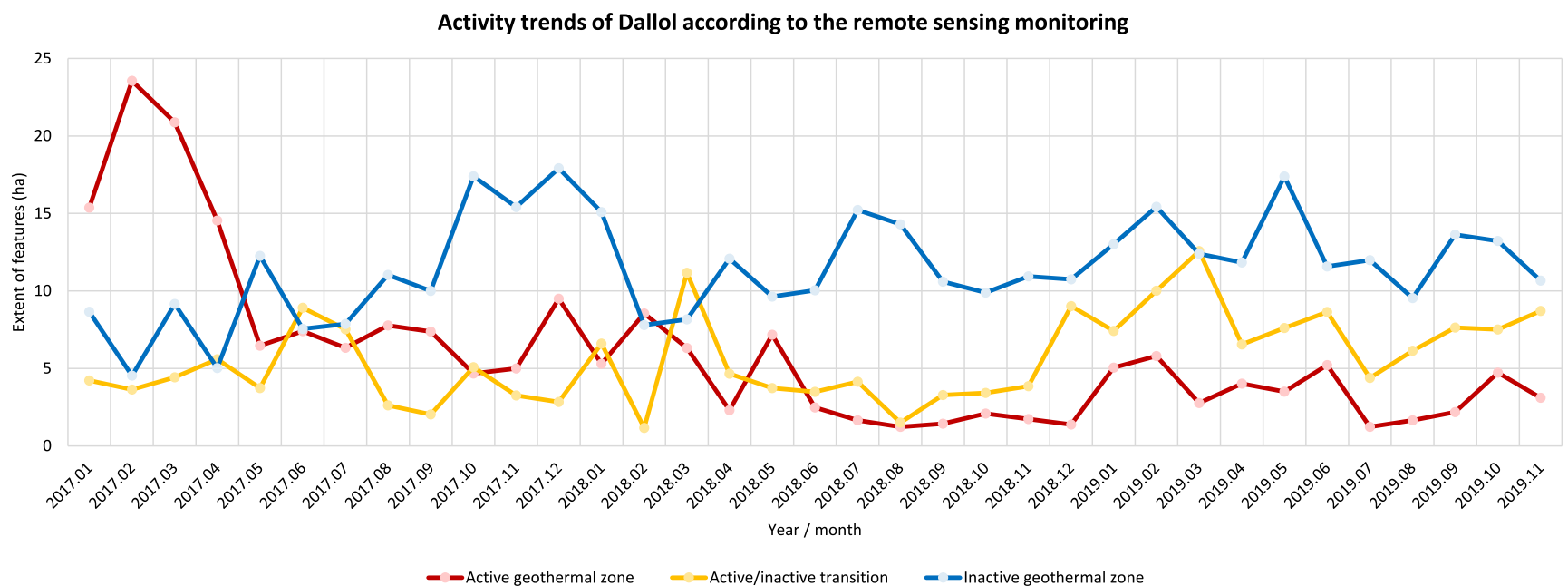

Fig. 8 Mount Dallol - changes of the extent of active, semi-active and inactive features between January 2017 and November 2019 
Geoheritage (2020) 12: 82

Page 11 of 34

82

Activity trends of Black Mountain according to the remote sensing monitoring

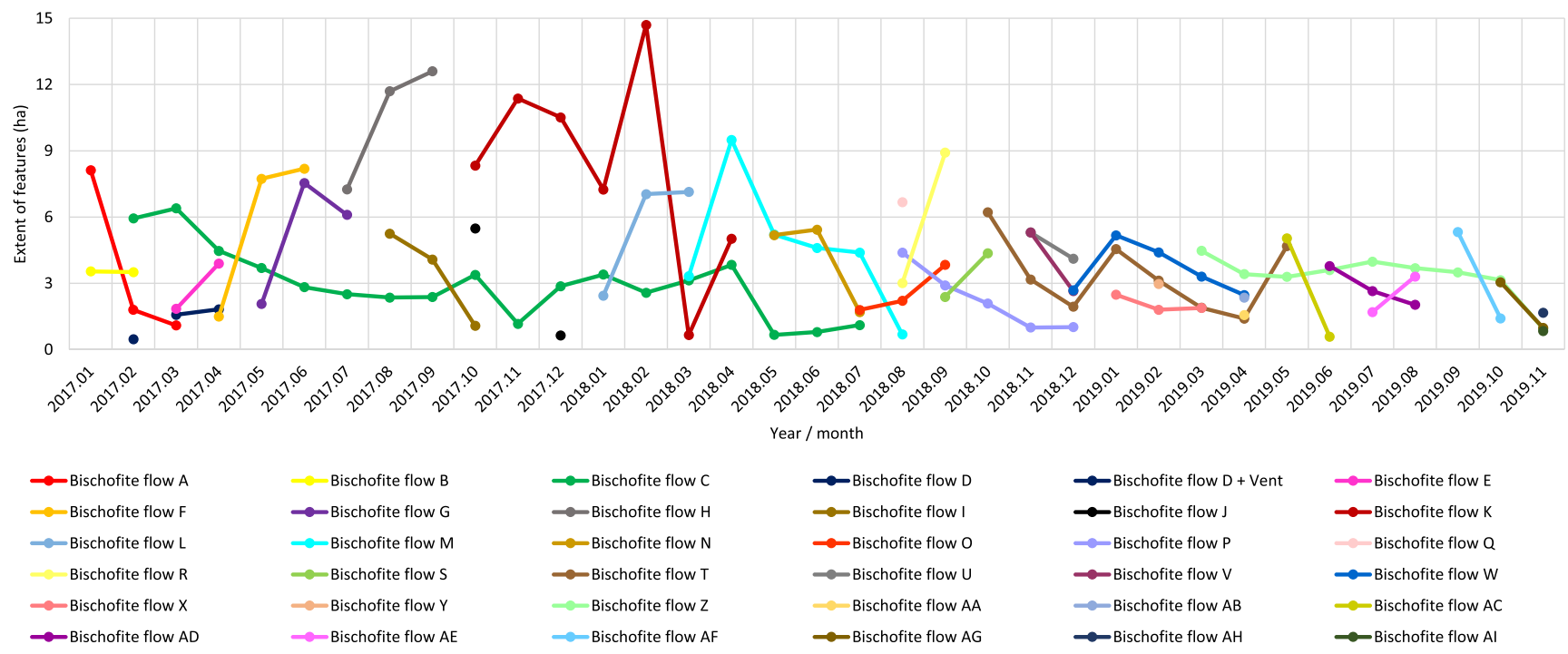

Fig. 9 Black Mountain - Changes of the extent of bischofite flows between January 2017 and November 2019

Black Mountain, the final thickness of this flow probably cheate enough topography to hinder its overflow by other units, or to be flooded.
Neither detailed geodetic survey of slope values nor drone surveys to create a high-resolution DEM have been carried out so far, but according to our field observations in 2017 and

Existence of bischofite flows at Black Mountain

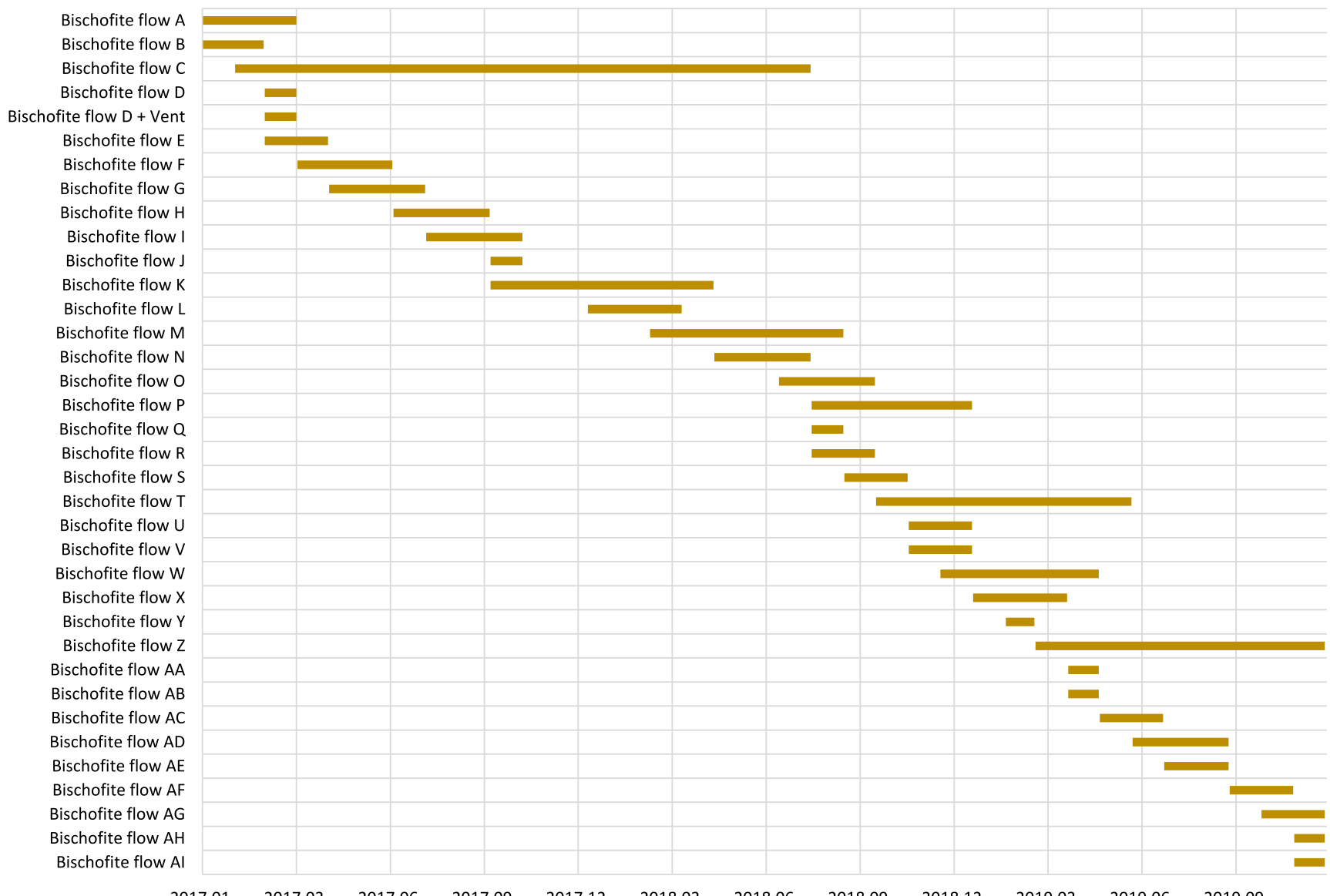

Fig. 10 The temporal persistence of bischofite flow generations from January 2017 and November 2019

Springer 
2019 , the slope gradient around the central vent is minimal (13 degrees). Thus, even small roughness features on the surface could divert the orientation of flows. Information about the intensity of upflows could be deduced indirectly from the values during the first appearance of each month and positive changes on areal extents between two subsequent months. A new flow generally covers less than 5 ha in area. Intensive further growth was observable for some flow generations, such as ' $F$ ', ' $\mathrm{K}$ ' or ' $\mathrm{R}$ '.

\section{Improving Visitor Resilience Through Web Publication}

The dataset of the monthly monitoring process obtained in this work, along with general features about visiting the Danakil Depression and Dallol, is made accessible on a website (http:// dallol.lmv.uca.fr/). The principal goal of the monitoring and its dissemination is to give a source of information to visitors, including guides, tourists and researchers, about the changing patterns of geothermal activity. The website's monthly mapping acts like a weather forecast, but it also gives a retrospective snapshot of the most recent situation (Fig. 11).

The interpretation and the deduced hazard maps are published as downloadable files that could be upgraded in the future to a webmap solution. Slideshows of raw satellite images also help follow up changes at Mount Dallol and Black Mountain.

The website also provides a basic, easily understandable summary of the geological features, description of the proposed geosites and useful information for visitors about the potential hazards. Moreover, it aims to be a forum for those who plan to visit the Danakil for touristic or research purposes.

\section{The Geosite Inventory of Dallol}

This study gives the first preliminary assessment of the geoheritage of Mount Dallol, Black Mountain and selected sites of Northern Danakil. The primary goal, by using a quantitative evaluation is to determine the geoheritage scientific importance of the Danakil Depression that could boost the conservation and protection of the site at a national, and hopefully an international level. Evaluating additional values such as educational or touristic potential could give an overview of their present situation and serve as an input for future recommendations. Finally, the geosite assessment with three different quantitative methods and comparison of the results provides the basis for a discussion about the best combination for Ethiopia, and potentially other countries where no consolidated geoheritage management practices are in place.

\section{Methodology of Inventorying and Assessment}

The selection process for potential geosites was conducted following the proposed workflow of Brilha (2016) and Reynard et al. (2016). A review of the limited literature

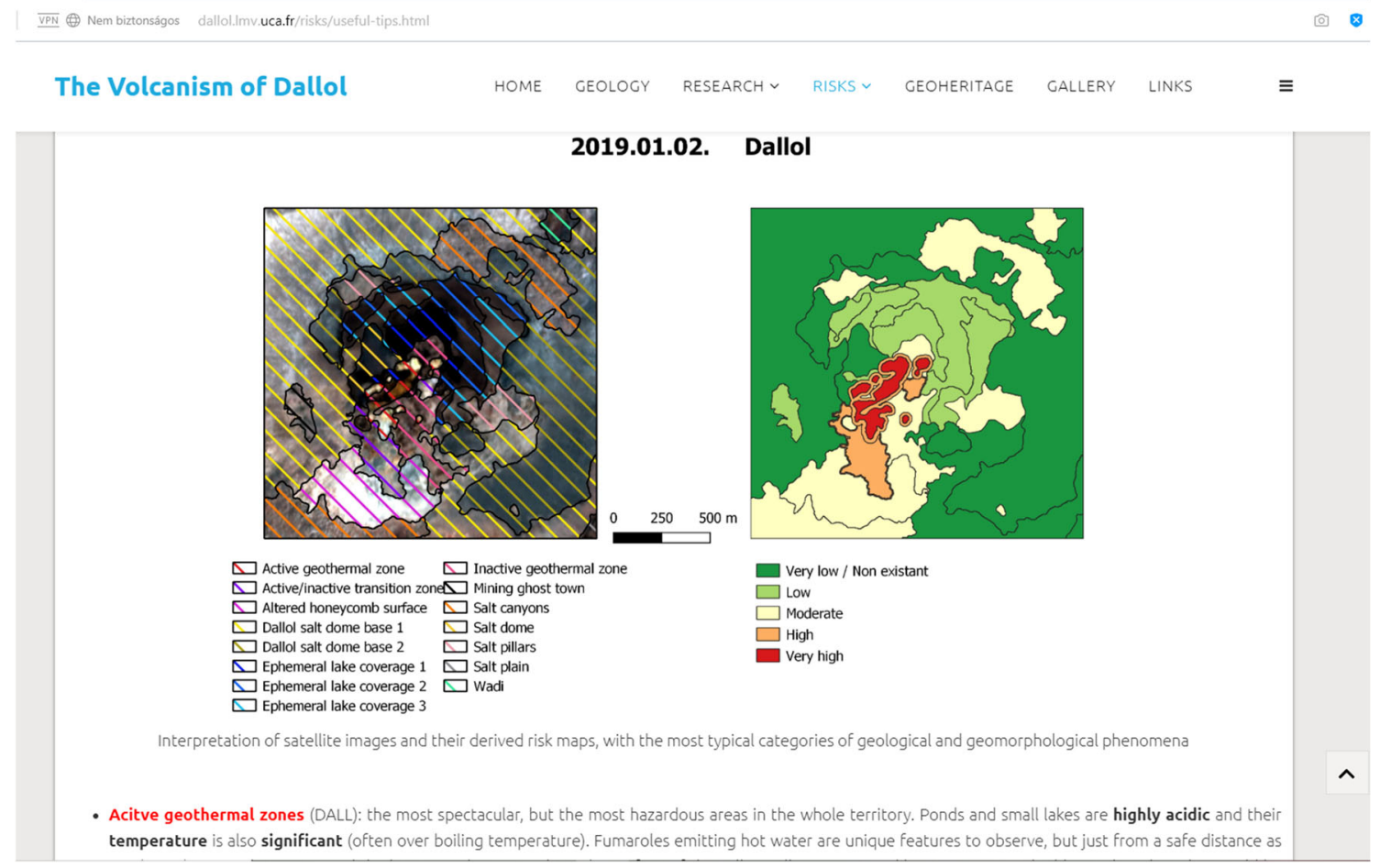

Fig. 11 Screenshot from the webpage with the maps of interpreted features and deduced hazard map 
and the concentration of present research activity around Dallol was an initial limitation in defining the extent of the inventory. Ultra-high spatial resolution satellite images are available for the entire area of the depression (Planet Labs Inc. 2020), but the lack of a correspondingly high-resolution digital elevation model limits the remote identification of potential important geomorphic features. Detailed field work in March 2017 and January 2019 (Vereb et al. 2019) was confined to the core area of Mount Dallol and Black Mountain due to the limited number of fieldwork days and environmental security constraints. Thus, the majority of the evaluated potential geosites are concentrated in these areas, and only a few others were assessed, close to the transport routes from Dallol to Hamed' Ela, the gateway village to the Danakil Depression. However, a list of potential geosites that should be evaluated in the future was also considered for the Ethiopian side of Northern Danakil, the territory defined by the Eritrean border to the north, the bajadas of the Balakia Mountains in the west, the Danakil Alps in the east and the northern perimeter of the Erta'Ale Range in the south. It includes potential features like the Round Mountain next to Dallol, fault-related features in the Balakia foothills, selected sites of the bajadas or the salt pan of Northern Danakil. This is a crucial element of not only geoheritage but also an area with associated intangible heritage of traditional mining. However, this extension of the inventory and the detailed evaluation of new geosites in the whole depression require further dedicated studies.

The dynamic nature of geologic and geomorphic features was an important consideration in defining the extent of dedicated geosites, which were based on a preliminary literature selection phase, and our fieldwork/monitoring. Representative features of active morphogenetic processes were observed, such as acidic lakes, bischofite flows and active fumaroles. The monitoring of the geothermal activity in part 2 has shown that these features change rapidly. This means that a feature representing an activity type could change, and a form might become inactive (e.g. fumaroles) or vanish by natural processes (i.e. drying out of acidic lake ponds, erosion and coverage of bischofite flows, collapse of representative salt pinnacles and pillars: Joyce 2009). Therefore, instead of small, distinctive geosites, larger, summary units are proposed, where each phase of landform evolution can be observed (Reynard et al. 2016).

The evaluation methods of Vujičić et al. (2011), Brilha (2016) and Reynard et al. (2016) were chosen because they use distinct and numerous criteria, allowing a predominantly quantitative assessment of all values, and they offer comparative case studies from different geographical regions (e.g. Moufti et al. 2015; Szepesi et al. 2017). In particular, the Reynard et al. (2016) method was used in order to allow future comparison with the first assessment case study of Ethiopia (Mauerhofer et al. 2017). The methodological descriptions, summarising the applied criteria, and the points system for the assessment can be consulted in the respective papers of Vujičić et al. (2011), Brilha (2016) and Reynard et al. (2016), and a short summary is given in the Appendix.

\section{The Preliminary Inventory - Results}

Thirteen geosites have been identified and inventoried in three spatial clusters, namely Dallol (6 sites), Black Mountain (4 sites) and the Northern Danakil (3 sites). Several of them are associated with constantly changing, highly active features (especially the geothermal manifestations), and the oldest site, the ancient shoreline (ND-03), is from the Pleistocene high stand, when a branch of the Red Sea occupied the area. Apart from one site (DA-06, the Parsons' Mining Camp), each site is natural, and human influence on the landscape is minimal. The list of geosites with their main characteristics can be consulted in Table 2, while their assessment is detailed in the 'Interpretation of Results - Discussion' section.

\section{Interpretation of Results - Discussion}

A direct comparison of the three methods is not possible due to the different evaluation criteria, the number and categorisation of sub-criteria, and the approaches of summarising and visualising the results. Vujičić et al. (2011) proposed a summary of results through a matrix; Reynard et al. (2016) enlisted numerous possibilities of cartographic visualisation, such as qualitative or multivariate representation of data per geosite; and Brilha (2016) did not include means of visualisation.

Consequently, in order to give an overview and comparison of the distinctive criteria, two sets of charts were created for each assessment method, described below, and then a possible quantitative comparison is presented.

\section{Individual Evaluation of Criteria for each Assessment Method}

The values of indicators (Vujičić et al. 2011; Reynard et al. 2016) and the sets of values (Brilha 2016) were plotted for each proposed geosite. Even with different approaches and a different number of questions, indicators with similar considerations were marked with a coherent colouring scheme: shades of blue for scientific and educational indicators, red for vulnerability and protection concerns, green for tourism, and orange for the aesthetic nature of the site.

Scientific values vary greatly per geosite, but it is clearly visible that, in most of the cases, they exceed half of the possible score for this indicator. Applying the methodology of Brilha (2016) and Reynard et al. (2016) (Figs. 13 and 14), 
Table 2 Short description of the proposed geosites of Dallol, Black Mountain and Northern Danakil with selected photos

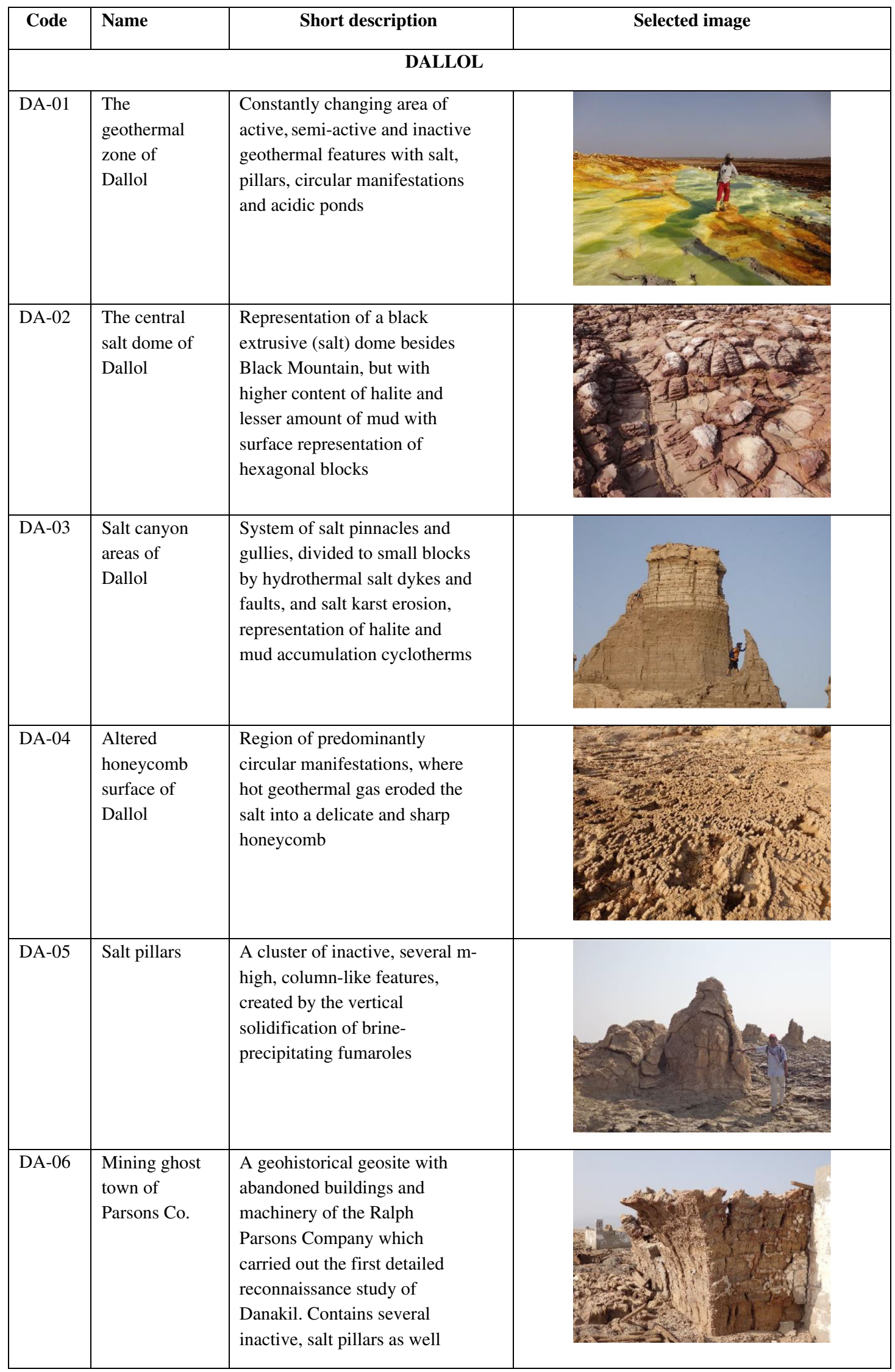




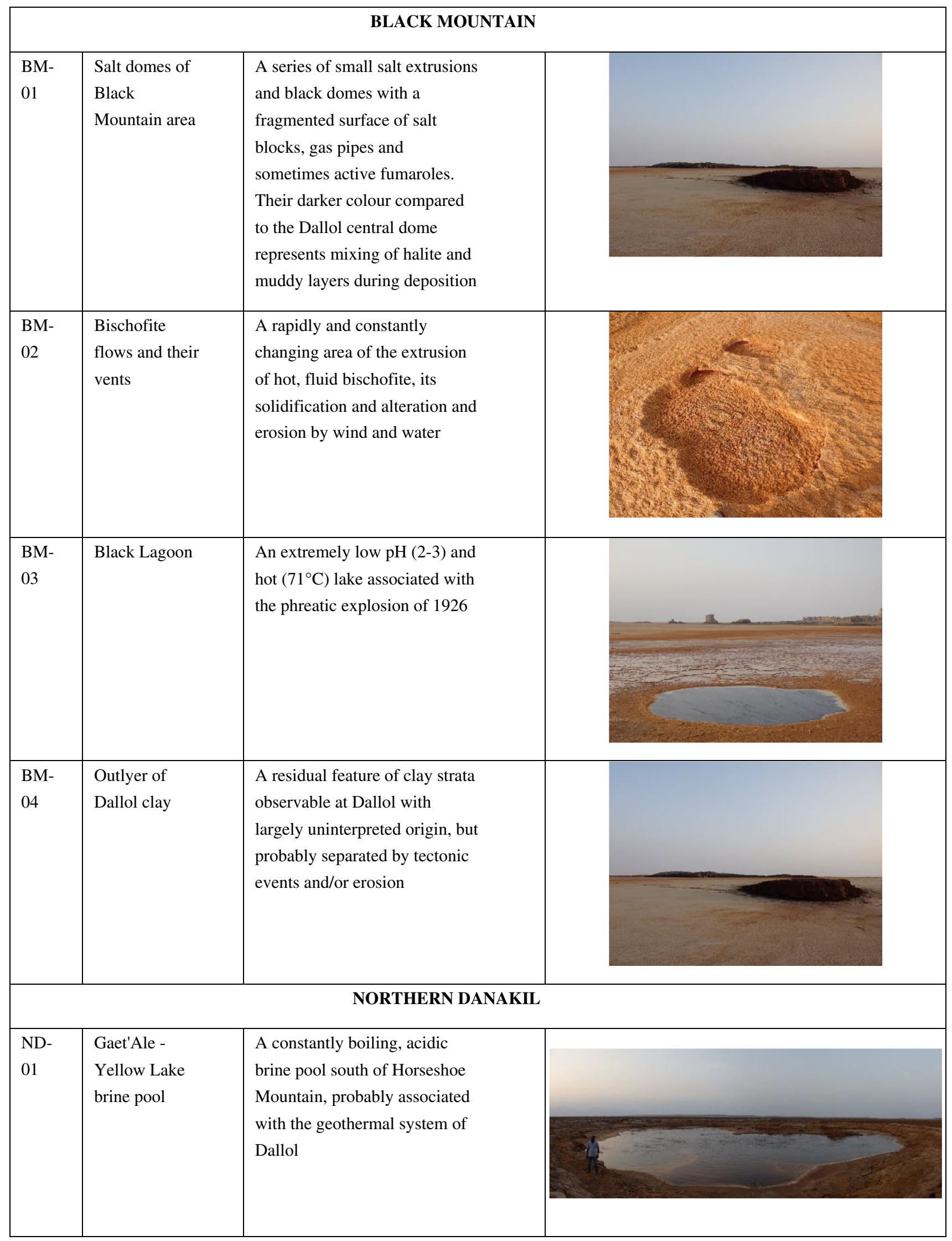




\begin{tabular}{|l|l|l|l|}
\hline $\begin{array}{l}\text { ND- } \\
02\end{array}$ & $\begin{array}{l}\text { Asale - } \\
\text { "Skating rink" }\end{array}$ & $\begin{array}{l}\text { Iconic topographic landmark } \\
\text { of the Dallol salt pan, brown to } \\
\text { red halite layers forming a ring } \\
\text { around a flat salt area. Probably } \\
\text { related to a small doming or } \\
\text { plug }\end{array}$ & $\begin{array}{l}\text { An excellent outcrop of the } \\
\text { Pleistocene sea-level, easy to } \\
\text { access, containing fossils of } \\
\text { Pleistocene flora and fauna } \\
\text { such as stromatolites and corals }\end{array}$ \\
\hline $\begin{array}{l}\text { ND- } \\
03\end{array}$ & $\begin{array}{l}\text { Ancient } \\
\text { sealevel } \\
\text { outcrop at } \\
\text { Hamed'Ela } \\
\text { road }\end{array}$ & $\begin{array}{l} \\
\end{array}$ & \\
\hline
\end{tabular}

the Parsons mining camp gets below 50\% of the total score, while applying that of Vujičić et al. (2011) (Fig. 12), two inactive geothermal manifestations, the altered honeycomb surface and the series of salt pillars are scored lower. Although a specific limit was not proposed by Brilha (2016) as a criterion of geosite based on scientific values, a score of $50 \%$ with the relevant evaluation method is a possible threshold for proposed geosites, and for geodiversity sites with moderate or irrelevant scientific importance.

Aesthetic or scenic considerations only appear directly in the method of Vujičić et al. (2011) and Reynard et al. (2016). The iconic geosites of the region, such as the geothermal zone of Dallol and the spectacular salt canyons that dominate the skyline from the depression, have the highest possible scores for all evaluations (Figs. 12 and 14).

Touristic values are measured quantitatively only by Vujičić et al. (2011) and Brilha (2016). It is clearly visible in Figs. 12 and 13 that touristic values are generally low compared with the scientific values, indicating that the sites have a high importance for geosciences, but their (geo)touristic use/ development is currently very minor. From a methodological viewpoint, it is interesting to note that the touristic values generally score close to the potential educational values when using the Brilha (2016) method, since these categories share 10 indicators that can be assessed similarly.

In each method, the indicators of current protection and vulnerability of the sites use different considerations; therefore, values are highly variable. High scores are given for most of the sites with Brilha's (2016) evaluation, because it measures the potential danger of degradation of the geosites
(Fig. 13). The outcrops of the Pleistocene seashore that is undergoing constant erosion next to the Hamed' Ela Berhale road, the geothermal manifestation of Dallol and the rapidly changing bischofite flows all reached significant values, as they could easily disappear or change irreversibly. The method of Vujičić et al. (2011) measures both the current protection status and the vulnerability of the site, and the obtained scores are generally moderate, indicating the lack of official protection despite the vulnerability of a site (Fig. 12). Applying the method of Reynard et al. (2016), the indicator of Ecological Values should be considered to be protection-related, but predominantly low scores are connected to this sub-criterion (Fig. 14). The Protected Site consideration got low scores at almost every site, as it is non-existent. The higher values for Black Lagoon, the Yellow Lake, and the geothermal ponds of Dallol, are related to the other sub-indicator, the Ecological Impact, as they function as potential niches for extremophile bacteria (Belilla et al. 2019). During field work, we observed many birds, including crows and swallows, suggesting that Dallol does provide an important environment, with insects as prey. However, to our knowledge, detailed studies about the assessment of local flora and fauna are still missing.

Two considerations appear as standalone indicators, which do not function as independent sets of values in other methods, or which are partially absorbed into an evaluation question. The Functional Values of Vujičić et al. (2011) are not direct elements of touristic development, such as road infrastructure, but they are an essential framework of it. Differences between the obtained values 
Geosite assessment of Dallol, Black Mountain and Northern Danakil - Indicators of Vujičcic et al 2011

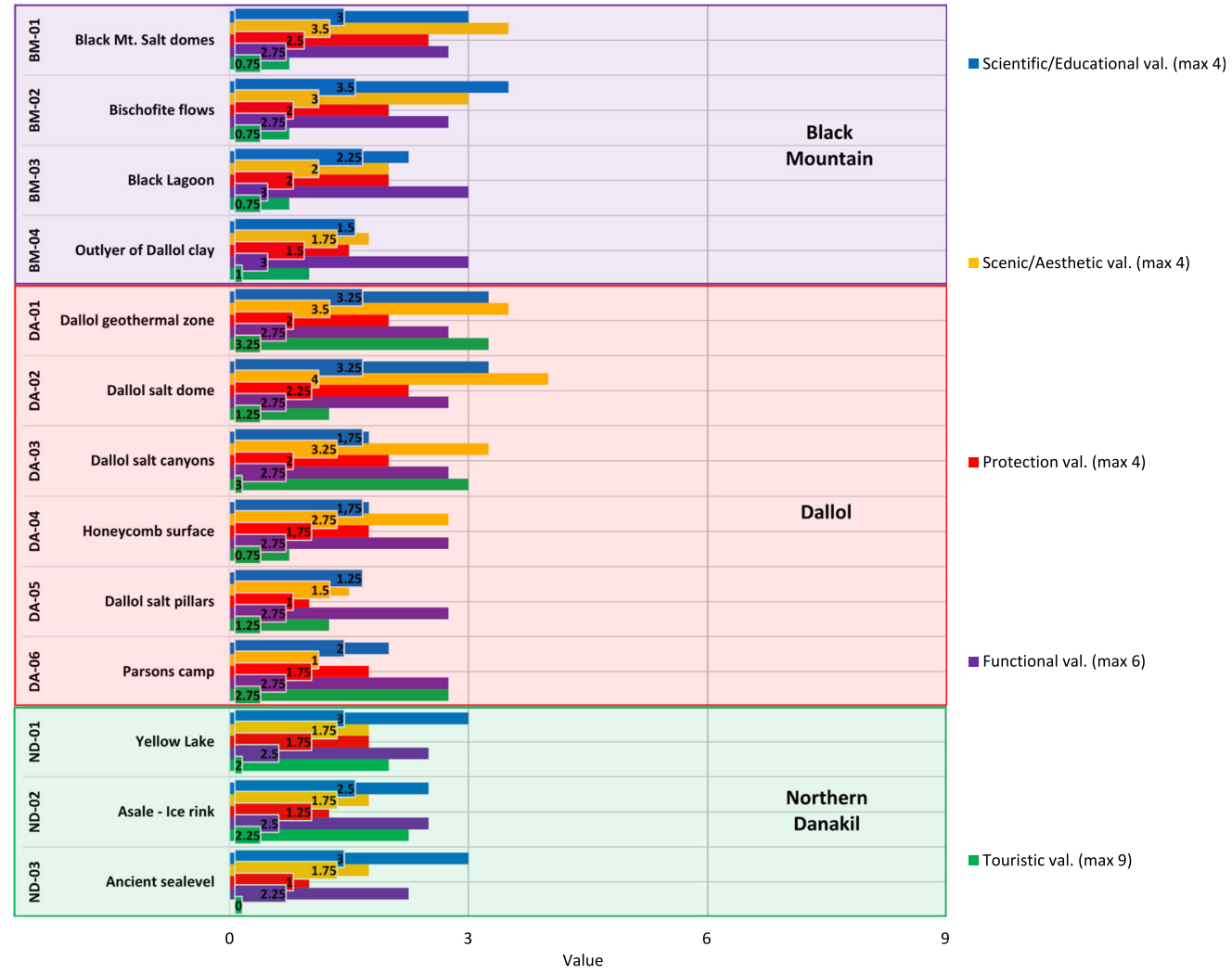

Fig. 12 Results of geosite assessment using the Vujičić et al. (2011) method with the individual indicators

Geosite assessment of Dallol, Black Mountain and Northern Danakil - Indicators of Brilha (2016)

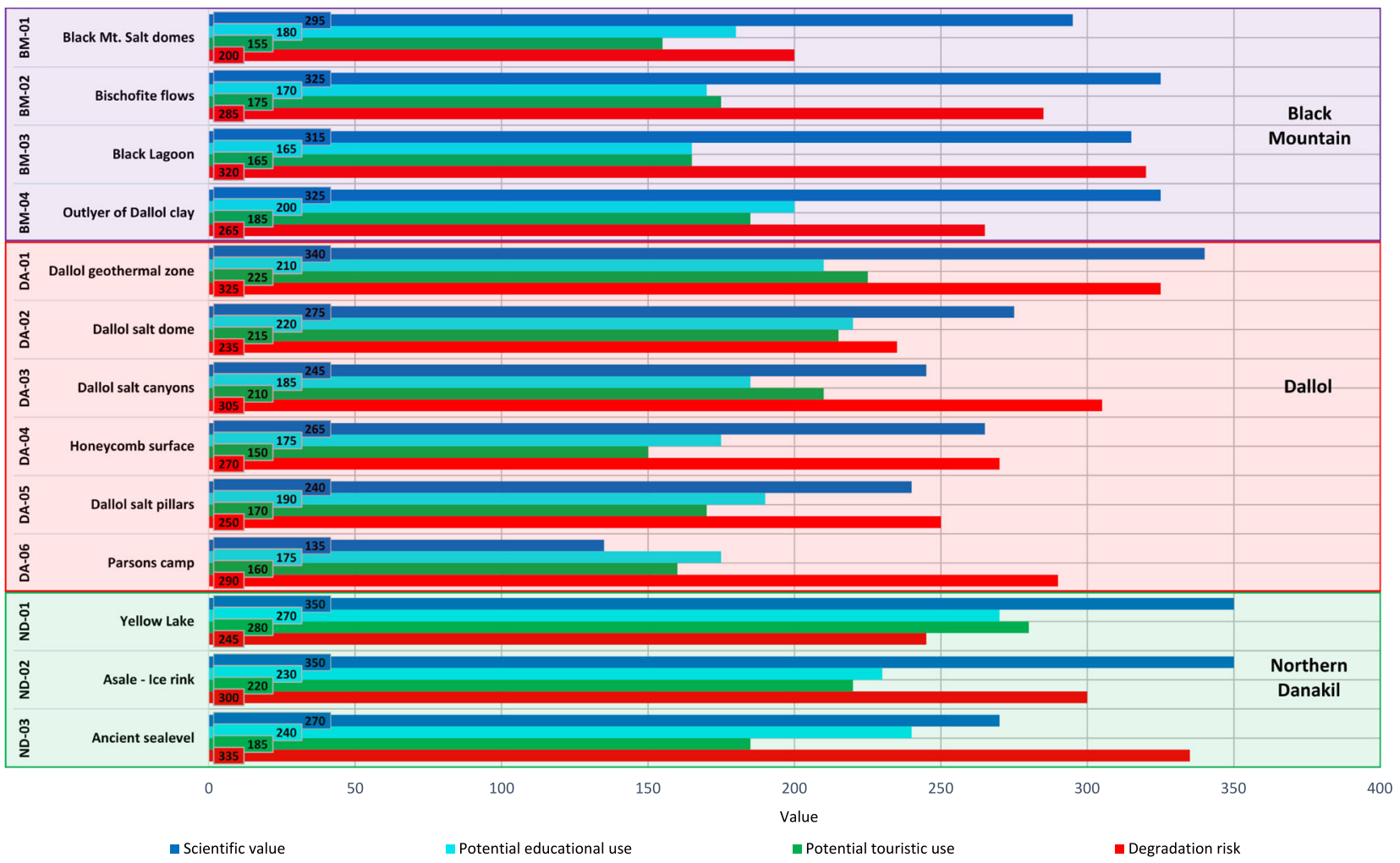

Fig. 13 Results of geosite assessment using the Brilha (2016) method with the individual indicators 


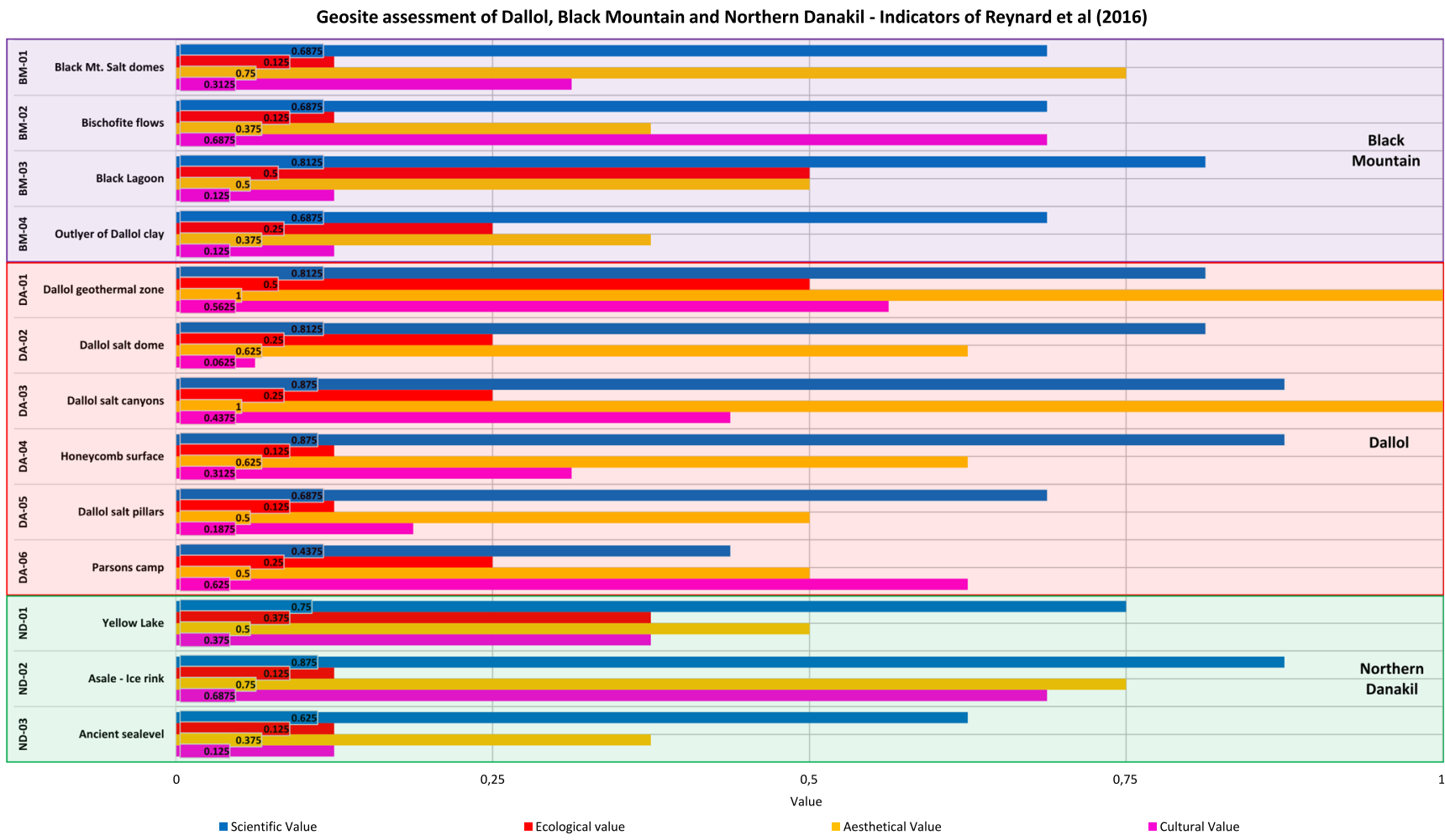

Fig. 14 Results of geosite assessment using the method of Reynard et al. (2016) with the individual indicators

are minimal, since the (lack of) infrastructure is uniform across all the territory of the Northern Danakil Depression (Fig. 12).

The other one is the Cultural Values of Reynard et al. (2016), also treated as a separate indicator group. Because cultural references are not evaluated in detail, both Brilha (2016) and Vujičić et al. (2011) restrict cultural values to a single question, Additional Anthropogenic Values and Association with other Values, respectively. This specific evaluation gives a current overview from the viewpoint of general cultural representation in geoscience literature and personal feedback from local guides, but future consultation with experts on the Afar culture and local people itself could improve the concept about the cultural impact of the geosites. Significant scores are related to sites of geohistorical importance and landmarks for the European explorers and miners, such as the Black Lagoon or the mining camp of Parsons Co. The Asale - 'Ice rink' and the geothermal zone of Dallol are also important sites for the local population, functioning as a landmark and water source, respectively (Fig. 14).

\section{Visualisation by Scatter Plots and their Interpretation}

The second type of visualisation was proposed by Vujičić et al. (2011) in the form of a scatter chart (Fig. 15). The Main Value of the site, calculated by the sum of Scientificl Educational, Scenic/Aesthetic and Protection values, is plotted against the Additional Values made up of Functional and
Touristic indicators. Although not described by Reynard et al. (2016), a similar representation can be done for this as well, because the concept of the evaluation is similar. In this case, Scientific Value is the Central Value that could be plotted against the Additional Values made up of Ecological, Aesthetic and Cultural indicators (Fig. 16). Brilha's (2016) method is different, as it does not create a final ranking based on a summation of the sets of values, but rather treats each of them separately, as seen on Fig. 13. However, apart from the Degradation Risk which is not considered as a value (Brilha 2016), the three sets of values (Scientific, Potential Educational and Touristic) can also be visualised, but preferably on a 3D scatter plot where each indicator set has its own axis (Fig. 17).

In comparing the positions of geosites in the scatter charts for each method (Figs. 15, 16 and 17), significant differences can be seen relating to the disparate number of sub-indicators included on the axes. Aesthetics are treated as a Main Value by Vujičić et al. (2011) (Fig. 15), while Reynard et al. (2016) included it in the Additional Values (Fig. 16). Aesthetics obtain high scores generally with both methods as described earlier; however, the different summation methods strongly affect the position of the geosites in the chart. The higher number of criteria for Scientific Values for Brilha (2016) and the numerous sets of values for Main Values by Vujičić et al. (2011) give a more dispersed array on this axis in both cases, while the Central/Scientific Value of 
Geosite assessment of Dallol, Black Mountain and Northern Danakil Summary of Vujičić et al 2011

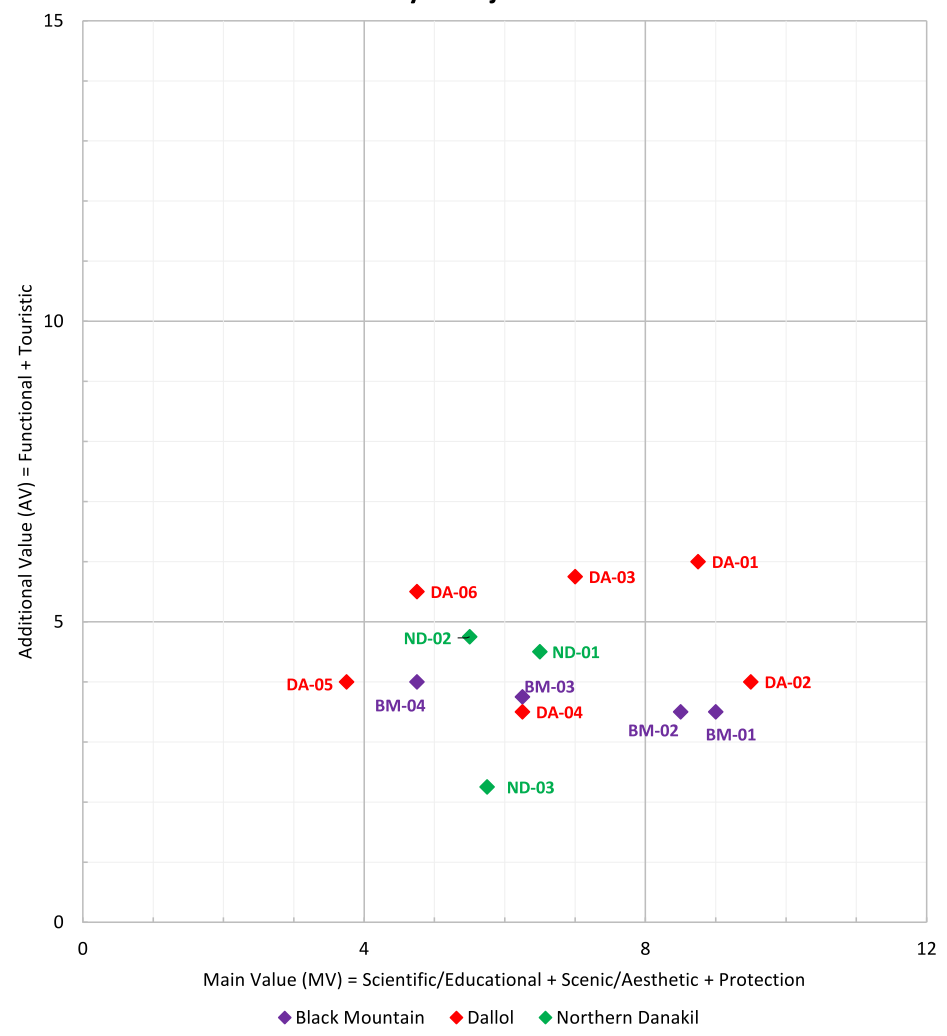

Fig. 15 The GAM matrix, the scatter of plot of the results using the method of Vujičić et al. (2011)

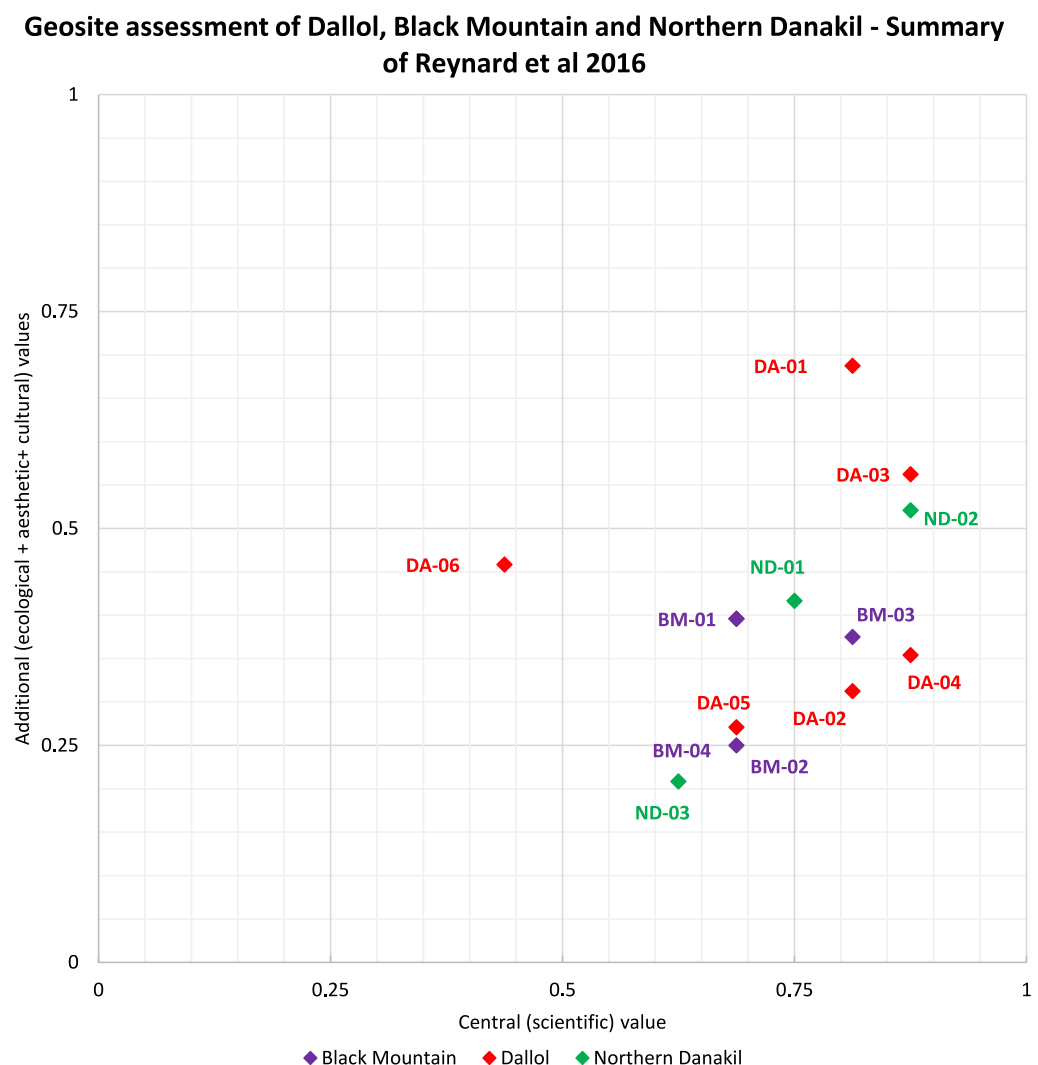

Fig. 16 Scatter of plot of the results using the method of Reynard et al. (2016) and applying the visualisation of Vujičić et al. (2011) 
Geosite assessment of Dallol, Black Mountain and Northern Danakil - Summary of Brilha (2016)
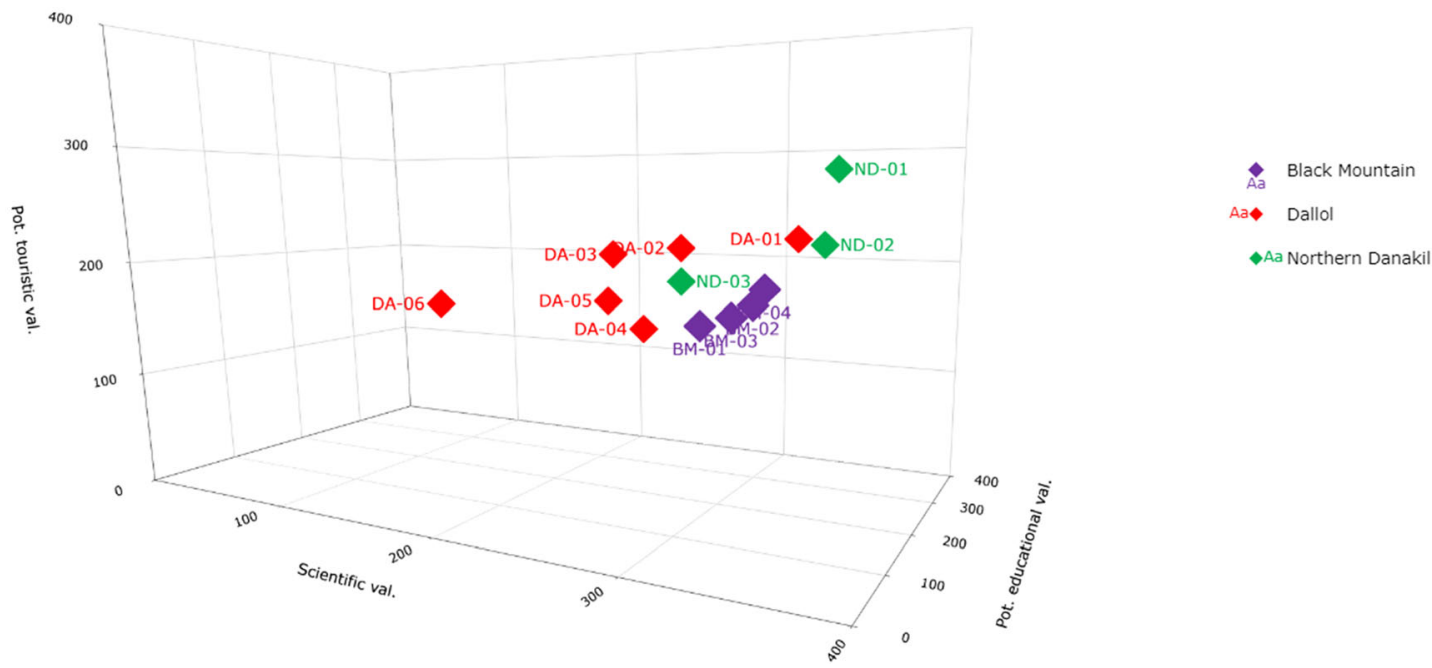

Fig. 17 3D Scatter of plot of the results using the method of Brilha (2016) without the Degradation Risk

Reynard only depends on the 4 sub-criteria; therefore, values of geosites in this respect tend to be close to each other (Fig. 16).

In all cases, the scientific indicator group has moderate to high scores, marking the scientific importance of the selected sites, and indicating that they should be validated as geosites. The only exception is the Parsons' Mining Camp (DA-06): applying both the Brilha (2016) and Reynard et al. (2016) method, it gets lower scores, because the geohistorical importance of the site is significant, but the intrinsic value of the geological features observable here, such as the highly eroded salt pillars, is moderate or low. In the case of the method of
Vujičić et al. (2011), the salt pillars of Dallol (DA-05) get the lowest Main Value, related to their moderate aesthetic value and vulnerability (Fig. 16).

Additional values are more concordant, with differences connected to the divergent input criteria. Both in the case of the method of Vujičić et al. (2011) and Reynard et al. (2016), these values are moderate to low (Figs. 15 and 16). Sites already visited by tourists score higher; therefore, their present touristic potential is already higher: for instance, the geothermal zone of Dallol (DA-01), the Yellow Lake (ND-01), the Asale - 'Ice rink' (ND-02) or the salt canyons of Dallol (DA-03). The same pattern is observable with the Potential Touristic Value of

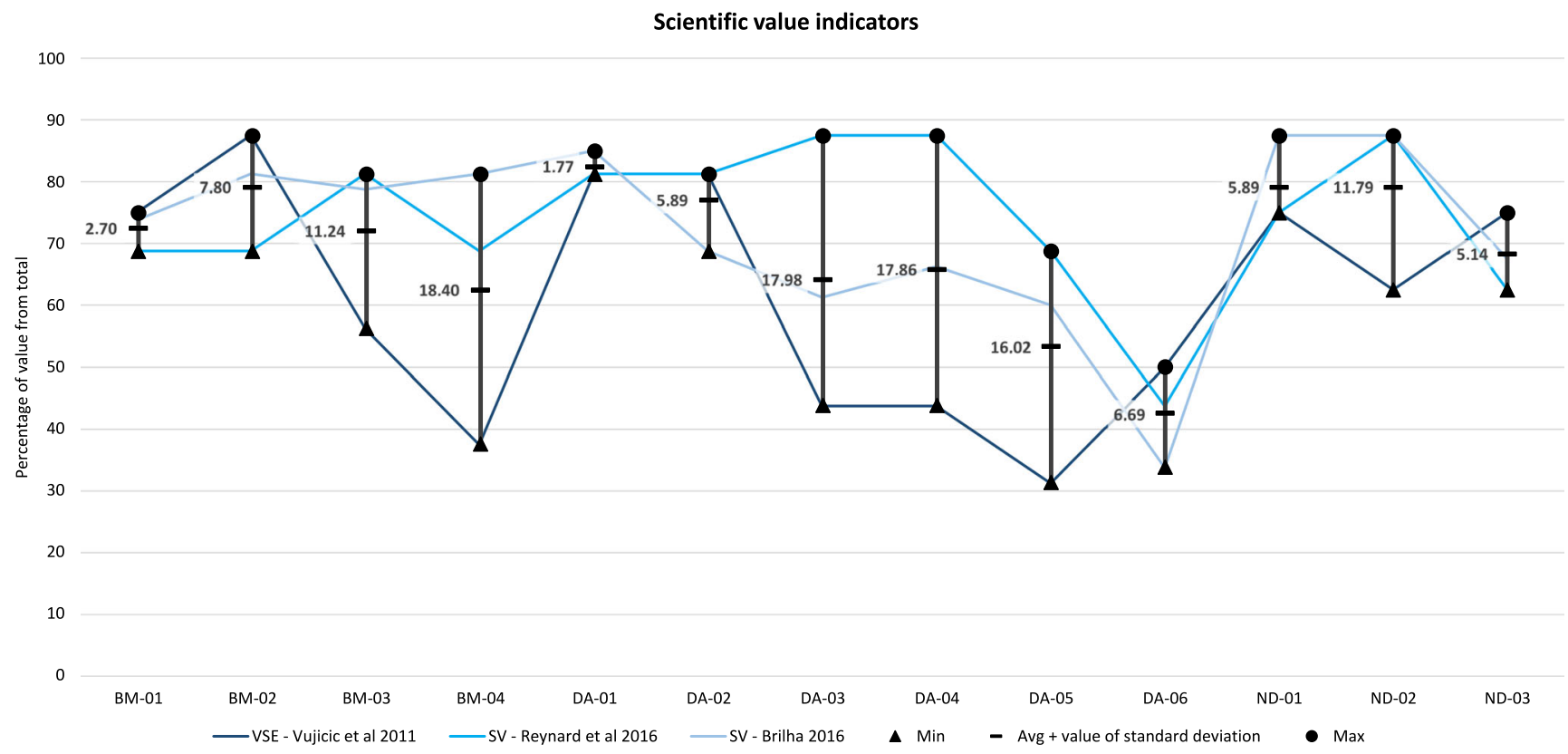

Fig. 18 Scientific value percentages per indicators using the method of Vujičić et al. (2011), Brilha (2016) and Reynard et al. (2016) 
Scientific + educational value indicators

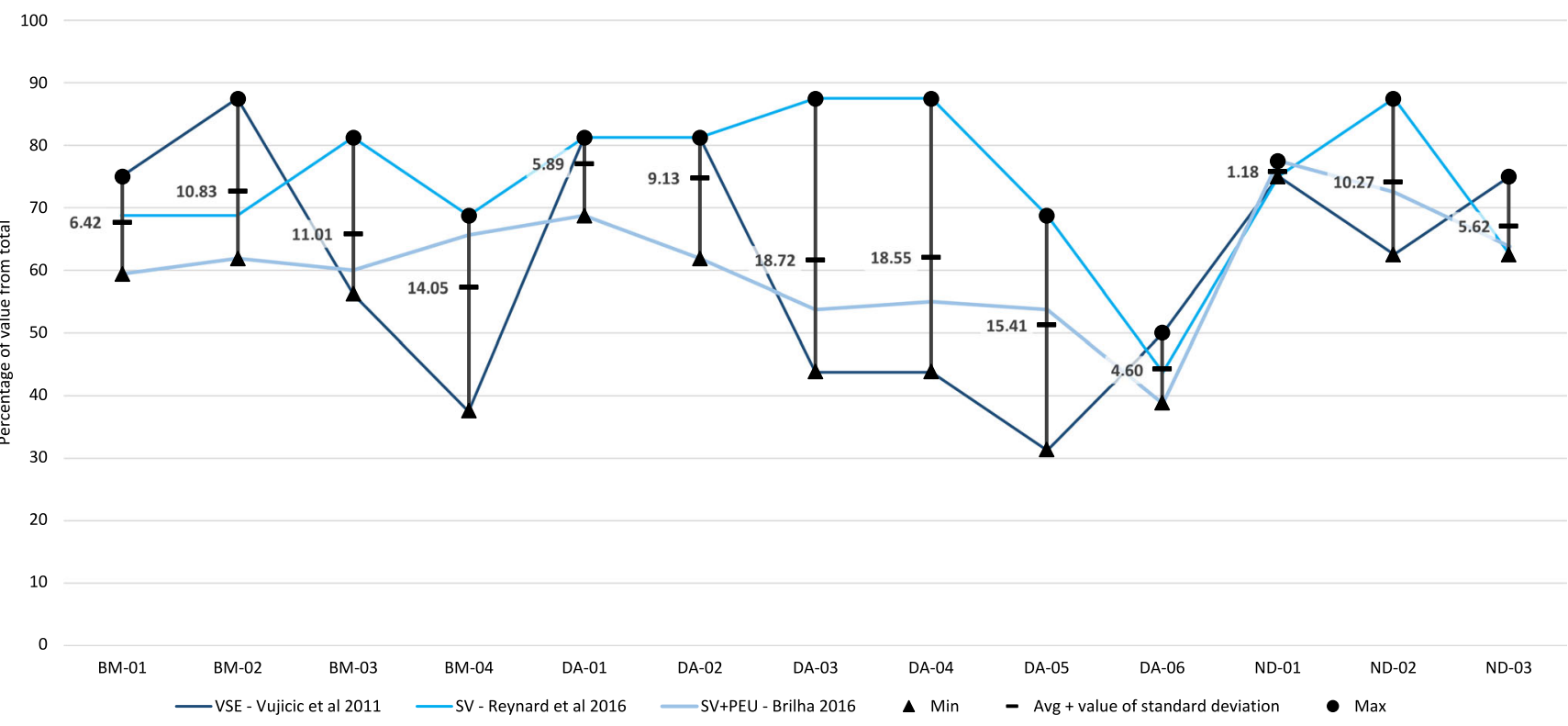

Fig. 19 Scientific value percentages including the potential educational value of Brilha (2016) per indicators using the method of Vujičić et al. (2011), Brilha (2016) and Reynard et al. (2016)

Brilha (2016) (Fig. 16). However, even these cases barely score $50 \%$ of possible values, indicating that they are not yet exploited sufficiently from the perspective of tourism. However, these results should be looked at within the context of each site, including aspects of their management. For example, geotouristic development of the outcrop of the Pleistocene sea level is not possible without reducing the vulnerability of the site (degradation of the roadcut outcrop), indicated by Brilha's (2016) evaluation method (Fig. 13).

\section{Quantitative Comparison of the Assessment Methods}

For the quantitative comparison of different assessment methods, the primary indicators applied in them were grouped as follows.

1 Scientific and educational indicators such as Scientific Value (SV) by both Brilha (2016) and Reynard et al. (2016) and Scientific/Educational Value (VSE) by Vujičić et al. (2011). The Potential Educational Value

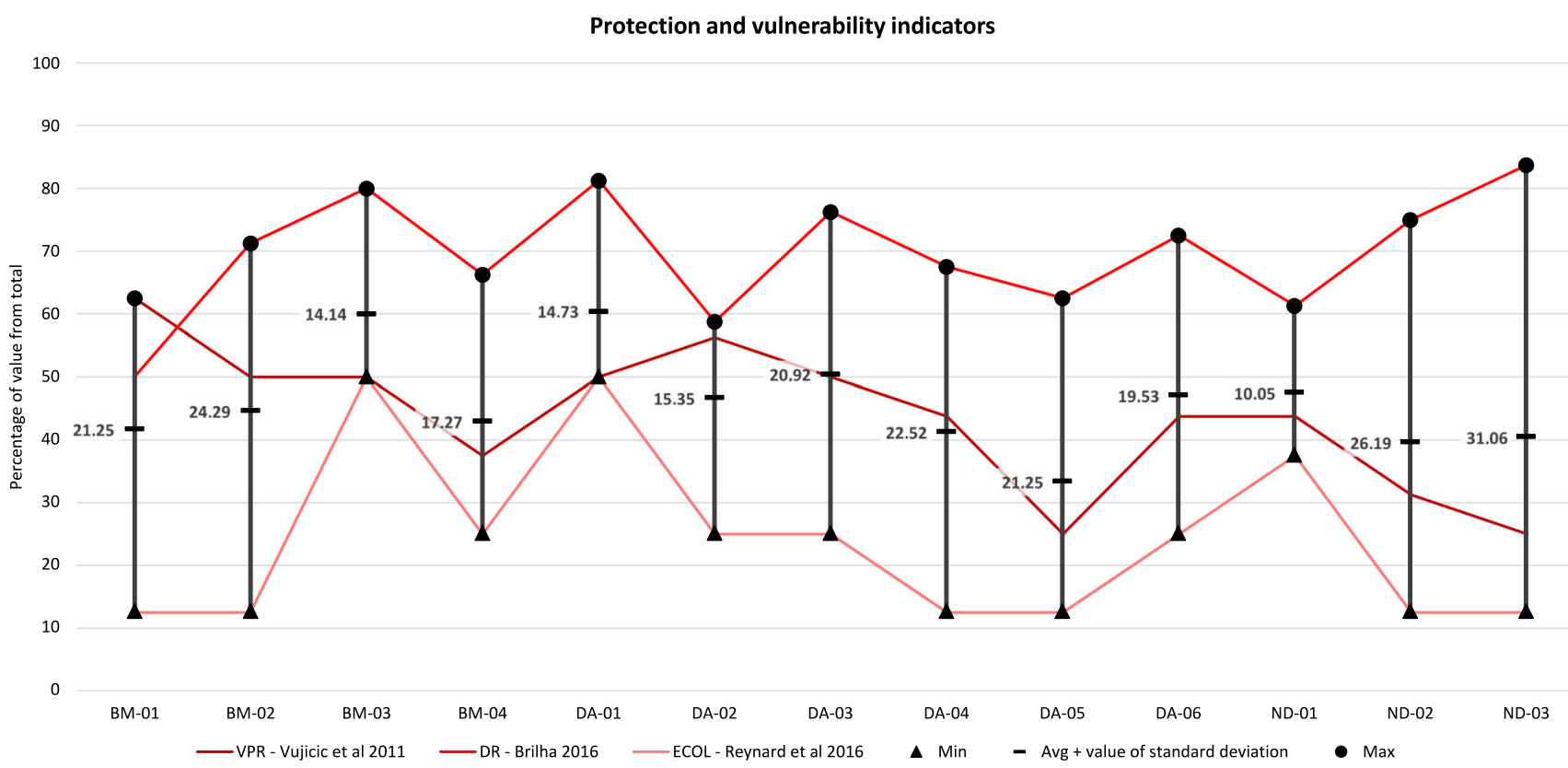

Fig. 20 Protection and vulnerability value percentages per indicators using the method of Vujičić et al. (2011), Brilha (2016) and Reynard et al. (2016) 
Touristic indicators

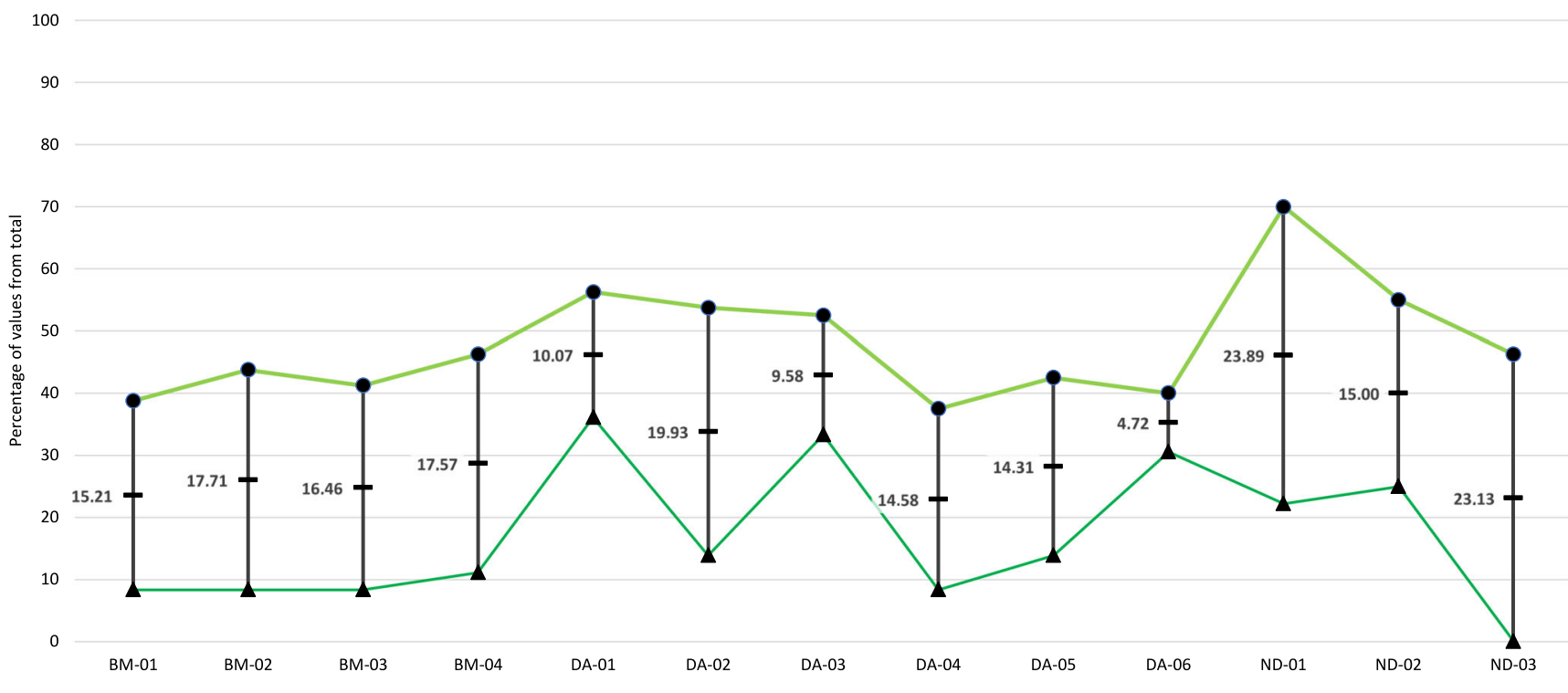

Fig. 21 Touristic value percentages per indicators using the method of Vujičić et al. (2011) and Brilha (2016)

(PEU) of Brilha (2016) was also placed in this group (see below).

2 Touristic indicators (Touristic Value (VTr) of Vujičić et al. (2011) and Potential Touristic Value (PTU) of Brilha (2016);

3 Aesthetics indicators (Scenic/Aesthetic Value (VSA) of Vujičić et al. (2011) and Aesthetic Value (AEST) of Reynard et al. (2016);

4 Protection and vulnerability indicators (Protection Values (VPr) of Vujičić et al. (2011), Degradation Risk (DR) of
Brilha (2016) and Ecological Value (ECOL) of Reynard et al. (2016).

Functional Value (VFn) is a fundamental factor for VTr, but it is not directly connected to touristic values according to Vujičić et al. (2011); therefore, it was not included in any of the groups, in the same way as Cultural Values (CULT) of Reynard et al. (2016).

The assessment methods use different scoring systems, $0-1$ in Vujičić et al. (2011) and Reynard et al. (2016), and 0-400

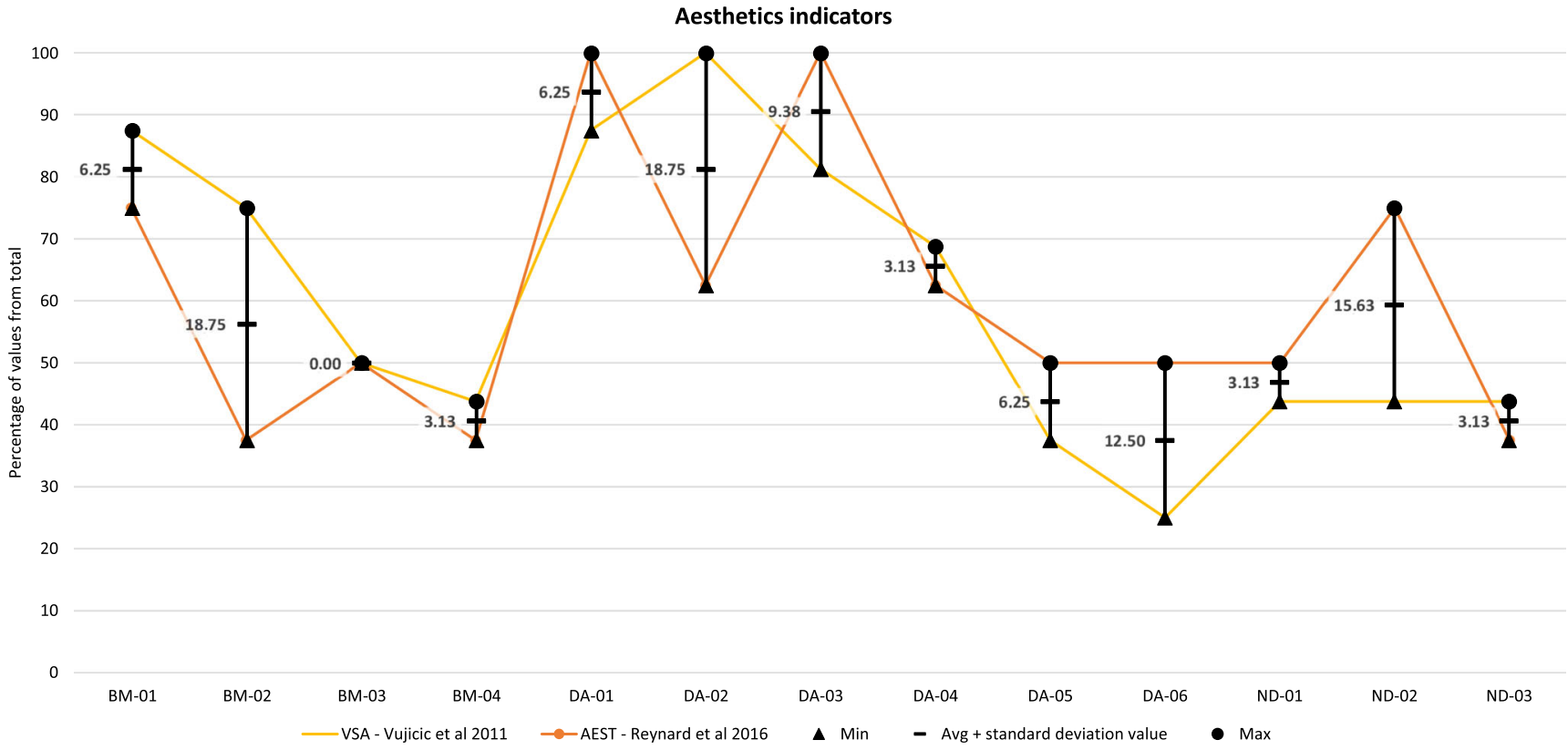

Fig. 22 Aesthetic value percentages per indicators using the method of Vujičić et al. (2011) and Reynard et al. (2016) 
(with a weighting) in Brilha (2016). In order to compare the results, each value was recalculated as a percentage of the maximum score. For each group of indicators, minimum, maximum, average and standard deviation values were calculated and plotted on charts with the percentage values of each assessment method (Figs. 18, 19, 20, 21, 22).

Scientific values are assessed with four sub-indicators using the method of Vujičić et al. (2011) and Reynard et al. (2016), contrary to Brilha's (2016) seven subindicators for the same. Comparing the obtained values and patterns (Fig. 18), the percentages of Vujičić et al. (2011) represent one of the extremities (minimum or maximum) in all 13 cases, while the same applies to the method of Reynard et al. (2016) in 11 cases (except the Outlier of Dallol clay and the Parsons' Mining Camp). In seven cases, they are at the opposite side of the range, while at 3 geosites (DA-01, the geothermal zone of Dallol; DA-02, the central salt dome of Dallol; and ND-01, the Yellow Lake in Northern Danakil), they both score the maximum or minimum values.

These 3 sites were amongst those with the lowest range of values and the lowest standard deviation. The similarity of scores for these geosites obtained by all methods underlines that their scientific significance is well-established, either low (DA-06, Parsons' Camp) or relatively high (BM-01, DA-01, DA-02, ND-01, ND-03).

The values achieved from Brilha's (2016) method highlighted two sites: they are the lowest values for DA-02 and DA-06. For 6 out of 13 cases, they range between the values obtained by the other two methods. This could be related to the higher number of criteria in Brilha's (2016) method, as well as the different question content for each method. Vujičić et al. (2011) and Brilha (2016) used well-defined scoring for every criterion (e.g. ranges for the number of publications about the area), while the method of Reynard et al. (2016) is more flexible, with considerations for evaluation defined rather than distinct values.

According to Brilha (2016), the Potential Educational Values (PEU) of geosites should not be summed with the other sets of values. However, in order to include this indicator in the comparison, we merged it with the Scientific Value by their arithmetical mean, based on the similar concept of Scientific/Educational Value in Vujičić et al. (2011). This approximate summing generally decreased the scores of Brilha (2016) due to the limited educational potential of the area (Fig. 18). Even so, highest values were reached for 6 sites compared with 13 for Vujičić et al. (2011) and 11 for Reynard et al. (2016).

Indicators concerning the protection and the vulnerability of sites are included in all methods (Fig. 20). Following the Brilha (2016) method generally awards the highest scores as it focuses on the potential degradation of the geosites, which was considered generally high due to the active geologic (geothermal manifestations) and geomorphic processes (erosion of salt formations, vulnerability of sites next to roads). In contrast, Reynard et al. (2016) evaluate the lack of legal and practical protection of geosites with low scores as these features are within the scope of Ecological Value (ECOL). Vujičić et al. (2011) give intermediate scores, since both the current protection level current condition, and the vulnerability of the site are included.

The prominent difference of touristic scores between the evaluation of Potential Touristic Value (Brilha 2016) and Touristic Value (Vujičić et al. 2011) is related partially to the number of criteria used for the evaluation (Fig. 21). The former uses 13 criteria in total, while the latter is restricted to 9. The structure of these questions also follows a different approach. Vujičić et al. (2011) measure the existence of touristic facilities (e.g. interpretation centres, restaurants) directly, in contrast to the more generalised sub-indicators of logistics of Brilha (2016). The lack of infrastructure resulted in minimum values for the GAM.

Aesthetics as an indicator was only measured by Vujičić et al. (2011) and Reynard et al. (2016). Contrary to the previously described variables, in this case, the dispersion of values is generally low, with no clearly visible trend between the two evaluations (Fig. 22), although the constraints in Vujičić et al. (2011) are more restrictive than the basic guidelines of Reynard et al. (2016). It might be connected with the subjective nature of aesthetics, compared with the more objective indicators of scientific relevance, tourism, etc.

\section{Comparison of Assessment Methods at Dallol}

Although the chosen geosite assessment methods of Vujičić et al. (2011), Brilha (2016) and Reynard et al. (2016) have different structures and considerations (therefore, they may be used effectively for different purposes in the broad domain of geoheritage), their quantitative results indicate a similar status for Dallol, Black Mountain and the selected sites of Northern Danakil.

The scientific value of the geosites is significant in almost all cases, and the quantitative evaluation has confirmed the conclusions of Holwerda and Hutchinson (1968), Gebresilassie et al. (2011) and Franzson et al. (2015) about the globally outstanding geological features of the Danakil Depression. However, their legislative and effective protection is insufficient (or non-existent), while their vulnerability is significant due to the highly active and rapidly changing natural processes.

All these conditions call for a dedicated plan for geoheritage management. Any management strategy should include considerations for geotourism. The results of the three evaluation methods clearly show that the current geotouristic potential of the geosites of Dallol is low, due to the lack of infrastructure, the long-term vision of management, the 
extreme climate and the regularly strained socio-political conditions. Therefore, significant efforts should be made to improve basic accessibility and interpretation of the area for tourists, while preserving the scientific values and paying attention to the potential hazards, such as vulnerability due to natural and anthropogenic factors.

Each assessment method has proven to be successful in giving a complex overview of the geoheritage of Dallol, but they highlight different aspects. For geotouristic development studies, we think that the method of Vujičić et al. (2011) gives the most comprehensive overview, with the directly tourismfocused questions and the related functional and aesthetics considerations, although the method of Brilha (2016) contains a higher number of dedicated criteria under Potential Touristic Value.

Assessment of the educational potential of geosites/ geodiversity sites was not the primary goal of this study due to the geographical and economic issues of possible school visits to the sites and the complexity of interpreting features. However, the large number of indicators of Potential Educational Value in the method of Brilha (2016) gave relatively low scores, showing that with a room for development, the area should be a key example for higher education in the long term. It might also be included in the curriculum of local Afari pupils, and it could become a global example using virtual or remote methods, thus minimising the need for visits, which cause risk problems for the site and the visitors.

From the viewpoint of geoconservation and geohazards, the vulnerability and protection indicators are crucial. Brilha's (2016) Degradation Risk gives the clearest interpretation of the vulnerability of sites, especially for the constantly changing geothermal features, while the methods of Reynard et al. (2016) and Vujičić et al. (2011) put emphasis on the lack of protection, therefore the need for legal and effective protection of the sites.

Finally, in terms of the scientific values, which should be considered the primary goal of any geosite assessment (Brilha 2018), all of the methods indicated a significant importance, despite their different evaluation criteria.

From the viewpoint of the evaluator, every method used shows advantages, while in other aspects, they perform less well compared with the others. The clear workflow or road map from the selection of sites to their assessment and synthesis in Reynard et al. (2016) and Brilha (2016) could be used not only for these quantitative and qualitative assessments but could also function as a standard for geosite assessments globally.

The well-defined scoring system of Vujičić et al. (2011) and Brilha (2016), with constraints on each value, reduces the subjectivity of evaluators, and makes it possible to compare the results with similar assessments of other areas. However, the given constraints are not scale-dependent; therefore, they might result in lower or higher scores, if adjustments to local conditions were not made. Reynard et al. (2016) is more flexible in this way, offering guidelines for each criteria rather than constraints, but this might be more subjective.

In terms of visualisation of results (important for decisionmakers), Vujičić et al. (2011) proposed a clear, easy-tounderstand method with the GAM matrix and Reynard et al. (2016) presented numerous ways of cartographic representation, while Brilha (2016) did not provide any suggestions on creating visuals. Considering the representation on charts, we have pointed out that the scatter plot visualisation of Vujičić et al. (2011) is also applicable to Reynard et al. (2016) and Brilha (2016) (in the form of a 3D scatter chart for the latter). It is also important to note that each indicator should be looked at independently (Brilha 2016), because summation or creation of a final ranking might hide conceptual details that can only be interpreted through the raw scores.

We are convinced that while each method has some benefits, the parallel use and comparison of multiple assessment methods would provide the most robust way of (i) characterising geoheritage values and (ii) raising appropriate questions required for development. Parallel application of a national, locally used method and an international one, or comparison of a number of international methods such as in the present paper are equally advantageous. There is no question that the application of the well-defined international quantitative methods, even though they require extra time, is worthwhile due to the more diverse overview of characteristics they give.

\section{Geohazards Resilience in Geoconservation and Geosite Assessment}

The methods presented here, as well as other ones, focus on the evaluation and protection of geoheritage, and tend to minimise or ignore the risks posed to visitors. In a hazardous environment, such as Dallol or other highly changeable areas, this is a serious shortcoming, which should be improved in the future by adding independent criteria assessing the hazards of the area, vulnerability of visitors, and thus the overall risk of the sites. The impacts of a hazardous event or a simple tourist accident could also be taken into account. The resilience of the local system depends on the number of visitors, the preventive education and preparation, and the mitigation in place (e.g. rescue or treatment facilities). At present, we would say that the level of resilience is low at Dallol, while the risk is significant, due to the geothermal and potential volcanic hazards, and the high vulnerability of tourists given the lack of prevention infrastructure and measures.

Our monitoring mission, the deduced hazard values and maps along with the safety proposals take an initial step in this direction. We suggest that the next steps should be the 


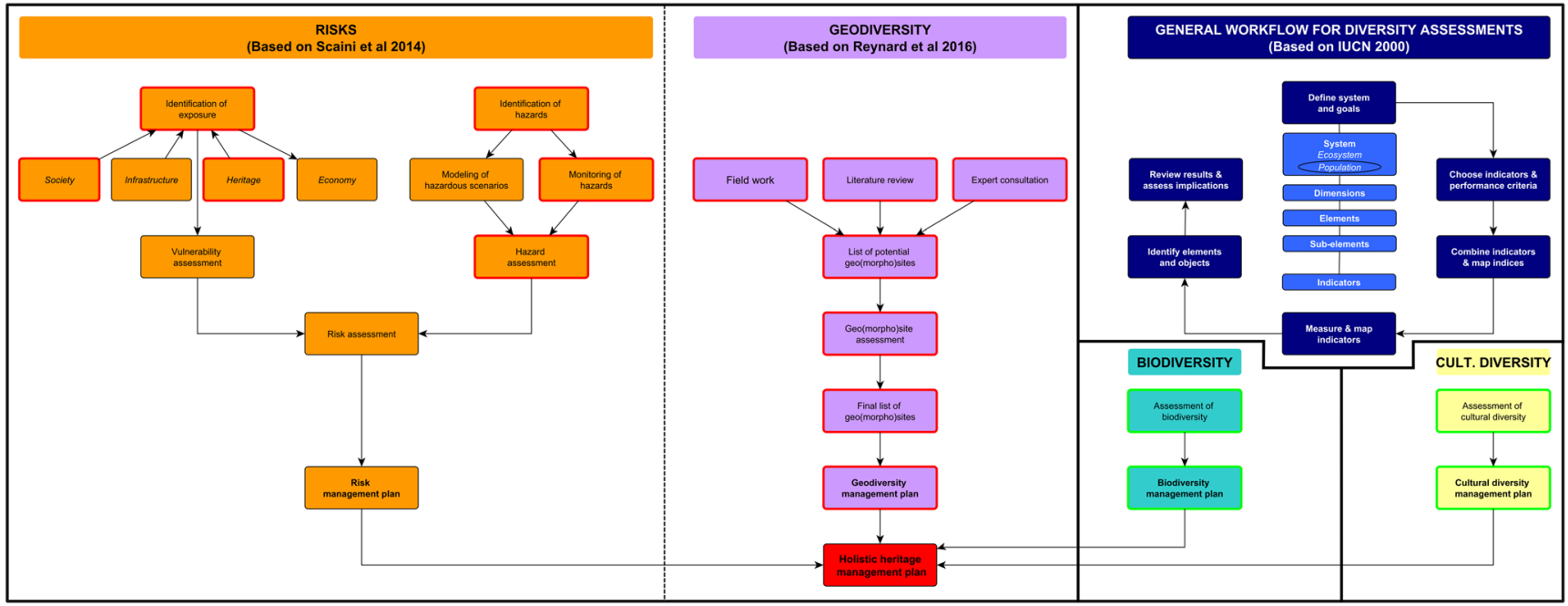

Fig. 23 A schematic proposal for a holistic heritage assessment and management approach. Red outlines indicate the steps carried out in the current research at Dallol, while green ones indicate steps carried out by Yara Inc. (ERM 2015)

inclusion of hazard, vulnerability and risk assessment methods (e.g. Ranke 2016) in geoheritage studies, and the elaboration of special hazard/vulnerability indicators for geosite assessment methods and geodiversity management practices. It should be integrated into a holistic approach, where the often separately conducted studies on the elements of natural and cultural diversity, the assessment of risks and their mitigation are put together into a complex heritage management plan (Fig. 23).

\section{A Preliminary Management Plan Proposal for Geoconservation and Geohazard Resilience - Synthesis}

A set of geoconservation and geohazard management guidelines were created based on the considerations of local geology, our preliminary satellite monitoring and comparative geosite assessment, as well as discussions with local stakeholders (experts from the University of Mekelle, local guides and Afari people).

We also took into account geoheritage aspects of other rift environments (such as the Chaîne des Puys - Limagne Fault, and Lake Malawi), and expanded the existing geomorphological heritage management proposal for the Simien Mountains in Ethiopia (Mauerhofer et al. 2017).

While our proposal does not function as a fully-fledged management plan, it is a compilation of recommendations and ideas, which could be used for discussion on the implementation of conservation and development plans related to the geoheritage of Dallol and Northern Danakil (Vereb et al. 2019).

\section{In Situ Monitoring of Geothermal Activity at Dallol}

The simple monitoring method, presented in this paper, provides a monthly overview of the extent of active and inactive geothermal areas, in particular the changes to bischofite flows, through satellite image interpretation. This can be expanded to include thermal images from satellites like Pléiades or ASTER. In order to gain deeper insight into the geothermal system, including changes in gas flux, fluid composition and temperature, an in situ monitoring system should also be installed. Investigation of the central crater of Dallol with the geothermal manifestations, the Black Lagoon, and the bischofite flow area at Black Mountain requires the installation of at least a simple webcamera, but preferably thermal cameras as well (McNutt 1996, Sparks et al. 2012). A long-term campaign aiming at the regular sampling of gas emissions and hydrothermal ponds is also needed, to expand present knowledge on chemical composition (Darrah et al. 2013).

\section{Designation of Visitor Routes with Respect to Geohazard Mitigation and Resilience}

At the time of writing (2019), visitors to the area do not follow a well-established trail, but rather a simple ascent through salt blocks from the 'parking lot'. In the geothermal zone, they can wander around freely under the rough supervision of tour guides, and it is easy to ignore potential hazards. Based on the almost 3-year-long dataset of activity patterns, and the level 4 or 5 hazard category areas, a safe visitor circuit was designated in the central area of Dallol and around the Black Mountain (Fig. 24). It does not mean that the spectacular, constantly changing landforms and 


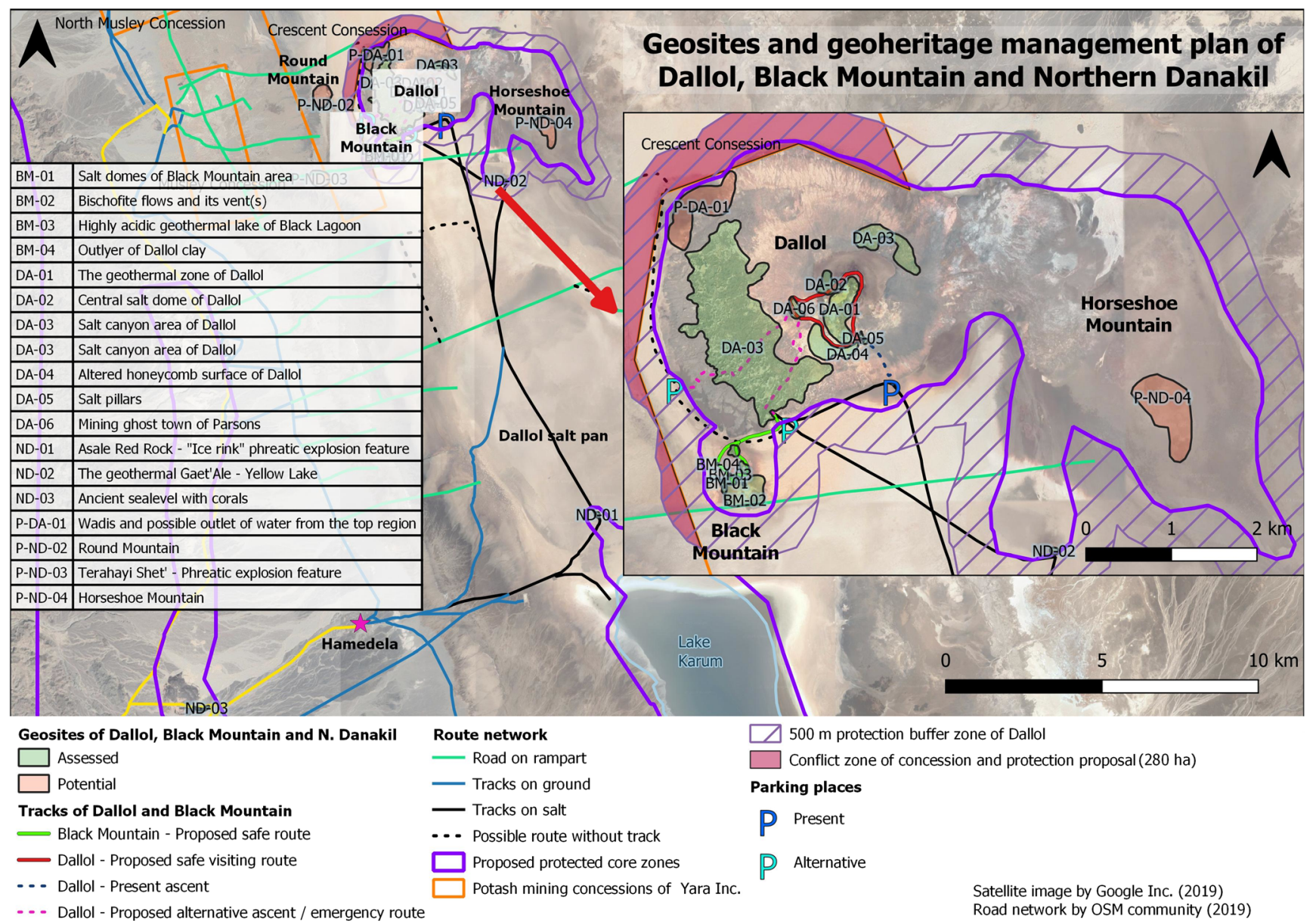

Fig. 24 Preliminary geoheritage management plan of Dallol and the Northern Danakil Depression

geological features should not be visited, but the circuit suggests the safest possible route. The visitors should be informed of what to do (by their guides, an interpretative panel, a website or application), especially in the case of a crisis event. Paving the trail or installing any infrastructure is not proposed, mostly in order to preserve the original state of the landscape, and also because of the potential change to the trail location depending on future changes in geothermal activity. Installation of small signposts is recommended at constant distances (e.g. every 200$500 \mathrm{~m}$ ) to clearly indicate the path and restrict walking off the trail.

\section{Alternative Ascent to Dallol, Inclusion of Less-Visited Geosites in Tour Packages}

The majority of visitors reach the area of Dallol from the south through the Berhale-Hamed' Ela paved road and then cross the salt pan of Dallol, starting their ascent to the central area from the closest 'parking lot'. To reduce the impact of linear pressure on the closest trail to the central 'crater', we propose alternative ascent routes (Fig. 24). Access by vehicles crossing south of the closest rampart of Dallol, or between the salt pinnacles and the Black Mountain, could also be possible.

A designated trail should run through the valleys of the salt canyon area through the Parsons Mining Camp to the central 'crater'. A second alternative is to establish a starting point at the meeting of the salt canyons and the Black Mountain, from where a trail could lead through the valleys between the pinnacles to the mining camp, and the circuit to the Black Mountain (Fig. 24). The latter is a partially existing route and regularly visited by tour groups. Each trail could be designated after consultation with tour guides and local Afari people, and the infrastructure requires basic signposting as well.

On the other hand, a preliminary investigation of increased visitor pressure on the hydrothermal system and the local ecosystem should be carried out before developing any trail. Alternative trails would not only reduce the pressure of present ascent routes but they could also function as evacuation routes in the event of hazardous natural events or accidents.

The majority of the tourist groups focus on the central area of Dallol, and some of them visit the southern salt canyon area, or Black Mountain. The Asale- 'Ice rink' phreatic landform and the geothermal pond of Yellow Lake are also 
popular stops. In addition, new sites could be added to the present tour packages, or new geotours could be created following assessment of other potential, but presently poorly known sites (where even a general geological and geomorphological description is lacking), such as the Horseshoe Mountain area, and important outcrops of fluvial fans and bajadas of the Balakia foothills (Fig. 24).

\section{Interpretative Facilities}

Currently, self-guided tours are not allowed in the Danakil and Afar Depressions: the area can only be visited in small groups with local Afari permission and armed escort. Therefore, infrastructure and methods for independent tours that work well in similar tourist destinations worldwide, such as geosites in geoparks, natural parks or World Heritage sites, are not applicable here, or only with modifications. However, certain measures could be taken in order to improve and supplement the personal interpretation of local guides. Installation of interpretation panels is not recommended due to the inexistence of self-guided tours, the general tendency of spending only a short time on geological explanations (Macadam 2018), the exposure of information material to extreme conditions, and the need for maintenance and renewal. However, synthetic panels should be placed at the present and future starting points of walking tours and ascents to the trails (Fig. 23), where important information about the geological background of Dallol and Danakil, potential hazards and their mitigation, should be included. A long-term development might include a more extensive network of interpretative facilities, such as an optimised website or application, thanks to the constant improvement of mobile data coverage in the area.

A partial reconstruction of a building of the old Parsons Mining Camp or installation of a traditional Afari-style hut at a safe distance might serve as a basic interpretation centre, illustrating the history of potash exploitation and the geothermal system of Dallol on some panels. It might also provide shelter and protection to tourists from the heat and unexpected events. An Afari-style stick construction would not protect against hydrothermal explosions, but the salt brick one could offer a basic, temporary refuge.

\section{Training for Tour Guides}

A significant number of tour operators provide guided tours of the Danakil Depression and Erta Ale (ETOA 2020). Although it is not stated explicitly in their tour packages, their activity is an indirect representation of geotourism, as the focal point of the visits here is the unique geoheritage of the area. Special courses for tour operators, background material and textbooks for tour guides about the geological phenomena could be implemented ensuring a scientifically correct, but understandable level of presentation. In the mid-term, a dedicated geotour service with qualified tour leaders should be established, with visits focusing specifically on local geoheritage (Mauerhofer et al. 2017). Although a detailed study is not available on the composition of tour groups, the majority of the visitors are from outside Ethiopia; therefore, language courses for the guides are also crucial. Tour operators are generally located outside the Afar region, especially in the Tigray Region and Addis-Ababa, with groups led by predominantly non-Afari people. In order to increase the involvement of the local population to boost the local economy, a higher number of Afari people could be included in the guided tours, who can contribute not just as escorts but also as guides, benefiting from their local knowledge of the environment.

\section{Geodiversity Management Plan on Potential Zones of Conflict of Interests}

In order to exploit one of the most significant potash deposits on Earth (Holwerda and Hutchinson 1968), several concession zones have been designated. The so-called Crescent Zone is a $35.3 \mathrm{~km}^{2}$ area exploration zone, awarded to Yara Dallol Potash Project, which surrounds Mount Dallol and the Black Mountain in a semi-circle from north to west. Originally, the area of Dallol itself was included in the concession zone, but it was relinquished by the Ethiopian Mining Laws (ERM 2015). However, the exploration area is still directly adjacent to the outer perimeter of Dallol, and it includes potential geosites as well, such as the Round Mountain or the Terahayi Shet' phreatic explosion feature (Fig. 23).

The current Environmental and Social Impact Assessment of the concession zone neither includes any reference to the geoheritage of the area nor does it provide a geodiversity management plan, in contrast to the biodiversity and cultural heritage management (ERM 2015). Moreover, the national legislative framework in Ethiopia does not make direct reference to geodiversity and management procedures and regulations (Asrat 2018). However, as a temporary solution, 'voluntary' measurements are proposed for the concession companies (namely the Yara Inc.), in order to prevent possible disturbance of landforms and geological processes in the contact zones of the concession and Mt. Dallol. In detail, we propose (i) to add an at least 500-m-wide buffer zone to the concession contract, where exploration/exploitation activities would be limited, and (ii) to ensure the protection of important geological features and the hydrothermal system inside the concession zone as well (Fig. 23).

The exploration companies could also be included in the geoconservation and geotouristic development investments, as part of the social responsibility expectations of the project (e.g. sponsorship of geotour-guide formation, implementation of basic tourist infrastructure). They could also benefit from such work, because natural hazards could impact mining 
operations, and management of tourism could reduce disturbance to the resource operations.

\section{Legislative Framework for the Protection of Geoheritage in the Danakil Depression}

Besides a small segment in the Awash National Park, the entire area of the Afar rift, including the Danakil Depression, lacks legislative protection both at a national and international level. The present study was restricted to the area of Dallol and selected parts of Northern Danakil, but the management and protection of the whole area should be considered, including sites and elements of the entire rift environment. Therefore, we propose that besides the ensemble of Dallol, and Black Mountain, further selected sites in the Northern Danakil, such as the salt pan of Dallol or Lake Assale, the surrounding Balakia Mountains and Danakil Alps, and the entire area of the Erta Ale Range, should be protected.

In line with the present Ethiopian legislative framework and regarding the importance of the area (Proclamation 541-2007), a national park might be proposed, namely the Afar Rift National Park or the AfarDanakil National Park (Vreugdenhil et al. 2012), with a focus on the geoheritage of the area. However, it must be noted that certain studies such as Tessema et al. (2010) and Abebe and Bekele (2018) raised significant concerns about the relationship of local communities to Ethiopian national parks, especially considering their management structure and regulations, which prohibit or interfere with traditional activities such as grazing.

The broadest inclusion of Afari people, especially the recognition of the intangible heritage of traditional salt mining at the Dallol salt pan, would be crucial in the study area. This activity has strongly reduced in recent years due to the challenge from industrial salt extraction and livelihood discrepancies between traditional activities and better paying sectors, such as recent road construction or even the booming tourism. Therefore, any conservation plan should ensure a balance between different present-day economic activities of the area, namely tourism, traditional and industrial mining and nomadic lifestyles.

A considerable alternative national legislative framework is the establishment of community (wildlife) conservation areas (Council of Ministers Regulations 163-2008). Although this designation is dedicated primarily for the community management of wildlife areas, its goals with supporting the inclusion of local communities from management to even revenues could work well in the Afari Region too. While it may need customisation for geoconservation, even preservation of local, extremophile elements of flora and fauna should justify such form of protection.
In the mid- to long-term, the global importance of the site as a primary example of active rifting processes potentially merits an international designation. Well-selected areas of national legislative protection should be considered for one of the two UNESCO designations for the protection of geoheritage:

- The World Heritage Convention through criterion VIII 'to be outstanding examples representing major stages of earth's history, including the record of life, significant on-going geological processes in the development of landforms, or significant geomorphic or physiographic features' (WHC 2017)

- 'The International Geosciences and Geoparks Programme, the mechanism of international cooperation by which areas of geological heritage of international value, through a bottom-up approach to conserving that heritage, support each other to engage with local communities to promote awareness of that heritage and adopt a sustainable approach to the development of the area' (UNESCO-IGGP 2015).

The international significance of geoheritage is given for both designations, but for a definite choice between the two labels, several aspects have to be carefully considered. For example, the broadest inclusion of Afari people would tie in with the Geopark bottom-up approach. On the other hand, due to the unique geological ensemble of the area, the outstanding universal value for a World Heritage application would be justifiable, especially considering the fact that geoheritage is still under-represented on this list (Dingwall et al. 2005). Even the precursory establishment of a national protection framework in the area, which is a prerequisite for all UNESCO designations, may affect this choice. The national park title supposes a stronger federal role in decision-making, which might be more easily transformed to a World Heritage site application, while community conservation areas or other regional, decentralised frameworks might back better the Geopark concept The authors of this study do not wish to indicate which of the approaches would be best (this is a matter for the Ethiopian authorities, amongst others), but they recommend a feasibility study for both the national level protection, and international designations.

Evaluating the reality of the proposed geoheritage management plan, we should consider that the Dallol area is both of industrial and tourist importance, so the potential damage and benefits of both areas should be integrated and weighed up. While it has been perceived that unconstrained mining might seriously damage the site, the impact of unconstrained tourism is potentially even more damaging. In addition, tourism and mining may both be affected by natural and socio-economical events, which can overlap, as illustrated recently (2013) when 
the Yara potash activities were affected by the formation of a large crater not far from the tourist routes (Franzson et al. 2015).

\section{Conclusion}

In this paper, we have addressed the problem of developing a geoheritage strategy for a poorly known and hazardous area, which is undergoing a tourist boom. Recent tourist deaths at volcanic and hydrothermal areas, such as at White Island (2019), Stromboli (2019), Pozzuoli (2016), and Ontake (2014), illustrate that there is a need to manage such geoheritage and tourist sites.

A holistic study of geohazards and geoheritage was presented on the globally outstanding, complex halovolcanic dome structure of Dallol and the adjacent Black Mountain. Observations of ongoing remote sensing monitoring and a geosite inventory with multiple aspects were used to set out some important management principles for the area, a baseline for a geoconservation plan that takes into account resilience to geohazards, and anticipates potential problems of the present tourist boom.

First, the monthly variability of the main geothermal features has been studied from 2017 to the present (October 2019). This has shown an overall decrease in geothermal activity in the central zone of Dallol, for example in the reduction of acid ponds. For Black Mountain, the monthly monitoring confirmed that the surface of bischofite flow areas is renewed frequently; a new flow is generally traceable for only 3 months, followed by its erosion or disappearance below a new flow feature.

Each geological-geomorphological unit was associated with a hazard value according to observations from satellite images and field work validation, which served as input to a monthly, five-scale hazard map, published on a website (Dallol 2020, http://dallol.lmv.uca.fr). It serves as a repository to follow up the rapid changes, and an advance information source for visitors.

In the second part of the study, a preliminary geosite inventory of Dallol, the Black Mountain and selected sites of Northern Danakil was made. Using parallel and comparative analysis of three quantitative methods of Vujičić et al. (2011), Brilha (2016) and Reynard et al. (2016), we were able to recognise the following:

- Moderate to high scientific importance for the 13 geosites, some of which, such as The Geothermal zone of Dallol (DA-01), suggests a global geoheritage importance.

- The current (geo)touristic values are limited due to the lack of dedicated infrastructure and no comprehensive management strategy; thus, there is a great potential for future development, an aspect also confirmed by the significant aesthetic values.

- Although the three methods chosen use different conceptual frameworks, the comparison of their results is possible. This could improve the objectivity of the geosite assessment, as the interpretation of results involves multiple perspectives.

- The assessment of geohazards is still not or only basically integrated into geosite assessment methods.

Finally, based on the results of our preliminary geoheritage assessment and the monthly monitoring project, a collection of geoheritage management guidelines was created, underlying key areas that could be addressed in detail in future studies:

- mitigation of geohazards in the active hydrothermal areas,

- future prospects for geotourism and education, with particular regard to improving the resilience of visitors through different geological phenomena (e.g. safety in active geothermal areas, effects of sea level changes on the example of the depression),

- considerations of legislative and effective protection: a holistic approach, connecting and cross-referencing detailed studies of disaster risk reduction, geoheritage and other elements natural (biodiversity) and cultural heritage (tangible and intangible).

These guidelines may serve as a basis from which further studies and documents could continue, with the expansion of the inventory to the whole Danakil Depression or the Afar rift, and pursuit of the satellite monitoring in the long-term, reinforced by in situ measurements. A broad collaboration of researchers from different domains, local inhabitants and natural resource exploitation companies is recommended for the valorisation of this globally unique area.

Acknowledgements High-resolution satellite images for the monthly monitoring are provided by Planet Labs Inc. (2020). The reconnaissance field trips of 2017 (Benjamin van Wyk de Vries \& Miruts Hagos) and 2019 (Viktor Vereb, Benjamin van Wyk de Vries, Miruts Hagos) were financed by Université Clermont Auvergne. The double-degree $\mathrm{PhD}$ research of Viktor Vereb on the connection of geoheritage and natural hazards in areas of different geographical environments and heritage management practices is financed by Campus France and the Hungarian state. Special thanks go to Amleset Gebreegzabher Gebrewahd for her help with contacting the Afar Region Cultural and Touristic Bureau. We would also like to express our special gratitude to the reviewers, who have further improved the manuscript with their suggestions during the review process. This research was conducted under the framework of UNESCO IGCP 692 - 'Geoheritage for Geohazard Resilience' project.

Author Contributions Implementation of the monthly monitoring process, the geosite assessment and its interpretation was carried out by 
Viktor Vereb. Benjamin van Wyk de Vries and Miruts Hagos helped with establishing the geoheritage management plan and the paragraphs of geological descriptions. Dávid Karátson has contributed significantly to the conceptual and textual coherence of the paper.

Funding Open access funding provided by Eötvös Loránd University. The authors received support from the Agence Nationale de la Recherche of the French government, through the programme 'Investissements d'Avenir' (16-IDEX-0001 CAP 20-25).

\section{Appendix}

Description of the geosite assessment methods used in the study

\section{Appendix 1. Method of Vujičić et al. 2011}

This entirely quantitative method uses 27 indicators, each evaluated with a grade between 0 and 1 . The indicators have two groups, the Main Values (MV) and the Additional Values (AV), summarised in Table 3. Results are represented on a matrix, where MV on the horizontal axis is plotted against AV on the vertical one (see Fig. 15 as an example). The matrix can be further divided into 9 zones, by trisecting both axes, where $Z(i, j)(i, j=1,2,3)$ and $i$ represents the horizontal and $j$ the vertical axis zone number. Each zone could give an overview of the present situation of a geosite and a quantified justification for future conservation and tourist development.
For example, $Z(3.1)$ indicates that the main values are significant, but additional values are low in this zone, implying sites with high scientific and/or aesthetical values; a low score of $\mathrm{AV}$ indicates that the geosite is not exploited yet by geotourism and/or significant development could be recommended.

Tomić and Božić (2014) published an extended version of GAM, the M-GAM (Modified Geosite Assessment Method), which includes the opinion of tourists concerning the importance of indicators in the assessment process. Each respondent rates the importance ( $\mathrm{Im}$ ) of the 27 GAM sub-indicators on a scale of $0-1$. The M-GAM values are calculated by the multiplication of the GAM values, generated by previous expert elicitation (Tomić and Božić 2014).

\section{Appendix 2. Method of Reynard et al. 2016}

The method of Reynard et al. (2016) is an updated version of Reynard et al. (2007), a predominantly quantitative geosite assessment method. From its two main groups, Central or Scientific Values are always assessed numerically, while this is optional for the Additional Values in the updated version of the method (Reynard et al. 2016). Each criterion is evaluated on a scale from 0 to 1 , and the sub-criteria are averaged using an arithmetic mean (Table 4). The Central Value of a site could be an average of its criteria (Reynard et al. 2007), but they could also be weighted according to the research purpose (Reynard et al. 2016).

Table 3 The summary of the method of Vujičić et al. (2011)

\begin{tabular}{|c|c|c|c|c|}
\hline \multicolumn{3}{|l|}{ Main values (MV) } & \multicolumn{2}{|l|}{ Additional values (AV) } \\
\hline Scientific/educational (VSE) & Scenic/aesthetic (VSA) & Protection (VPr) & Functional (VFn) & Touristic (VTr) \\
\hline Rarity & Viewpoints & Current condition & Accessibility & Promotion \\
\hline Representativeness & Surface & Protection level & Additional natural values & Organised visits \\
\hline $\begin{array}{l}\text { Knowledge on geoscientific } \\
\text { issues }\end{array}$ & Surrounding landscape & Vulnerability & Additional anthropogenic values & $\begin{array}{l}\text { Vicinity of visitors } \\
\text { centre }\end{array}$ \\
\hline \multirow[t]{6}{*}{ Level of interpretation } & $\begin{array}{l}\text { Environmental fitting of } \\
\text { sites }\end{array}$ & $\begin{array}{l}\text { Suitable number of } \\
\text { visitors }\end{array}$ & Vicinity of emissive centres & Interpretative panels \\
\hline & & & $\begin{array}{l}\text { Vicinity of important road } \\
\text { network }\end{array}$ & Number of visitors \\
\hline & & & Additional functional values & Tourism infrastructure \\
\hline & & & & Tour guide service \\
\hline & & & & Hostelry service \\
\hline & & & & Restaurant service \\
\hline $\mathrm{MV}=\mathrm{VSE}+\mathrm{VSA}+\mathrm{VPr}$ & & & $\mathrm{AV}=\mathrm{VFn}+\mathrm{VTr}$ & \\
\hline
\end{tabular}

Each sub-indicator marked on a rank of 0-1 (0.25 Likert-scale). Some indicators limited to 0, 0.5 and 1 values (Vujičić et al. 2011)

Modified Geosite Assessment Method (M-GAM) by Tomić and Božić (2014): each sub-indicators' importance (Im) assessed by individual visitors in the following way

$\mathrm{M}-\mathrm{GAM}=\operatorname{Im} * \mathrm{GAM}=\operatorname{Im} *(\mathrm{MV}+\mathrm{AV})=\frac{\sum_{k=1}^{K} I v k}{K} *((\mathrm{VSE}+\mathrm{VSA}+\mathrm{VPr})+(\mathrm{VFn}+\mathrm{VTr}))$, where $I v_{k}$ is the score of one visitor for each subindicator and $K$ is the number of total visitors 
Table 4 The summary of the method of Reynard et al. (2016)

\begin{tabular}{|c|c|c|c|}
\hline \multirow[t]{2}{*}{ SCIENTIFIC VALUE (SV) } & \multicolumn{3}{|l|}{ AdDitional VALUE (SV) } \\
\hline & Ecological Value (ECOL) & Aesthetic Value (AEST) & Cultural Value (CULT) \\
\hline Integrity (Int) & ecological impact (EcI) & viewpoints (VP) & religious importance (REL) \\
\hline Representativeness (Rep) & protected site (PS) & contrasts, vertical & historical importance (HIS) \\
\hline Rarity (Rar) & & development and space & artistic and literature importance (ART) \\
\hline Paleogeographic value (PgV) & & structuration (SIR) & geohistorical importance (GEO) \\
\hline & & & economic value (ECON) \\
\hline$S V=\frac{I n t+\operatorname{Rep}+\operatorname{Rar}+P g v}{4}$ & $\begin{array}{l}E C O L=\frac{E C I+P S}{2} \\
A V=\frac{E C O L+A E S T+C U L T}{3}\end{array}$ & $A E S T=\frac{V P+S T R}{2}$ & $C U L T=\frac{R E L+H I S+A R T+G E O+E C O N}{5}$ \\
\hline
\end{tabular}

Each criterion is marked on a rank of 0-1 (0.25 Likert-scale). Quantitative assessment of AV is facultative in Reynard et al. (2016); weighting of indicators are possible

\section{Appendix 3. Method of Brilha (2016)}

Four set of indicators are defined in this quantitative method (Table 5.), where Scientific Values (SV) and Degradation Risk (DR) should be assessed in all cases, since scientific importance is the crucial requirement of a geosite and the characterisation of degradation is a minimum requirement for any conservation and management plan. Assessment of Potential Educational (PEU) and Touristic Values (PTU) can also be evaluated for geotouristic or geoeducational development plans, and these values are inevitable for geodiversity sites which do not possess scientific significance. For the two latter sets of values, 10 indicators are common and should be assessed from both educational and touristic viewpoints where they contain 2 and 3 standalone criteria. Each indicator is marked on a scale of 1 to 4 , with two remarks: score 3 is omitted at SV in order to better distinguish the score 4 sites from lower scoring ones, and 0 can be given as a value where it is irrelevant. Each indicator is weighted by its importance, summing up to 100 per set of values. The final value is given by multiplying the scores of each criterion by these weights, and it should total in 400 in each case (SV, PEU, PTU, DR).

Table 5 The summary of the method of Brilha (2016)

\begin{tabular}{|c|c|c|c|c|c|c|c|}
\hline \multicolumn{2}{|l|}{$\begin{array}{l}\text { SCIENTIFIC VALUES } \\
(\mathrm{SV})\end{array}$} & \multicolumn{2}{|c|}{$\begin{array}{l}\text { POTENTIAL EDUCA-TIONAL } \\
\text { VALUE (PEU) }\end{array}$} & \multicolumn{2}{|l|}{$\begin{array}{l}\text { POTENTIAL TOURISTIC } \\
\text { VALUE (PTU) }\end{array}$} & \multicolumn{2}{|l|}{$\begin{array}{l}\text { DEGRADATION RISK } \\
\text { (DR) }\end{array}$} \\
\hline Criterion & Weight & Weight & Criterion & Criterion & Weight & Criterion & Weight \\
\hline \multirow{2}{*}{$\begin{array}{l}\text { A. } \\
\text { Representative- } \\
\text { ness }\end{array}$} & \multirow[t]{2}{*}{30} & 10 & \multirow{2}{*}{\multicolumn{2}{|c|}{$\begin{array}{l}\text { A. Vulnerability } \\
\text { B. Accessibility }\end{array}$}} & 10 & \multirow[t]{2}{*}{ A. Deterioration of geological elements } & \multirow[t]{2}{*}{35} \\
\hline & & 10 & & & 10 & & \\
\hline B. Key locality & 20 & 5 & \multirow{2}{*}{\multicolumn{2}{|c|}{$\begin{array}{l}\text { C. Use limitations } \\
\text { D. Safety }\end{array}$}} & 5 & \multirow{3}{*}{$\begin{array}{l}\text { B. Proximity to areas/activities with potential to } \\
\text { cause degradation }\end{array}$} & \multirow[t]{3}{*}{20} \\
\hline \multirow{2}{*}{$\begin{array}{l}\text { C. Scientific } \\
\text { knowledge }\end{array}$} & \multirow[t]{2}{*}{5} & 10 & & & 10 & & \\
\hline & & 5 & \multicolumn{2}{|l|}{ E. Logistics } & 5 & & \\
\hline D. Integrity & 15 & 5 & \multicolumn{2}{|c|}{ F. Density of population } & 5 & & \\
\hline \multirow{2}{*}{$\begin{array}{l}\text { E. Geological } \\
\text { diversity }\end{array}$} & \multirow[t]{2}{*}{5} & 5 & \multicolumn{2}{|c|}{ G. Association with other values } & 5 & C. Legal protection & 20 \\
\hline & & 5 & \multicolumn{2}{|l|}{ H. Scenery } & 15 & D. Accessibility & 15 \\
\hline \multirow{5}{*}{$\begin{array}{l}\text { F. Rarity } \\
\text { G. Use limitations }\end{array}$} & 15 & 5 & \multirow{2}{*}{\multicolumn{2}{|c|}{$\begin{array}{l}\text { I. Uniqueness } \\
\text { J. Observation conditions }\end{array}$}} & 10 & \multirow[t]{5}{*}{ E. Density of population } & \multirow[t]{5}{*}{10} \\
\hline & 10 & 10 & & & 5 & & \\
\hline & & 20 & $\begin{array}{r}\text { K. Didactic } \\
\text { potential }\end{array}$ & $\begin{array}{l}\text { K. Interpretative } \\
\text { potential }\end{array}$ & 10 & & \\
\hline & & 10 & $\begin{array}{l}\text { L. Geological } \\
\text { diversity }\end{array}$ & L. Economic level & 5 & & \\
\hline & & & & $\begin{array}{l}\text { M. Proximity of } \\
\text { recreational areas }\end{array}$ & 5 & & \\
\hline
\end{tabular}

Each criterion assessed on a rank of $1-4.0$ values are permitted. Value of 3 is omitted at SV, maximum points of 400 per each sets of values (SV, PEU, PTU, DR), with the multiplication of criterion points with the weighting 
Open Access This article is licensed under a Creative Commons Attribution 4.0 International License, which permits use, sharing, adaptation, distribution and reproduction in any medium or format, as long as you give appropriate credit to the original author(s) and the source, provide a link to the Creative Commons licence, and indicate if changes were made. The images or other third party material in this article are included in the article's Creative Commons licence, unless indicated otherwise in a credit line to the material. If material is not included in the article's Creative Commons licence and your intended use is not permitted by statutory regulation or exceeds the permitted use, you will need to obtain permission directly from the copyright holder. To view a copy of this licence, visit http://creativecommons.org/licenses/by/4.0/.

\section{References}

Abebe FB, Bekele SE (2018) Challenges to national park conservation and management in Ethiopia. J Agric Sci 10(5):52-62. https://doi. org/10.5539/jas.v10n5p52

ARCTB (2019) Afar Region Cultural and Touristic Bureau (information request)

Asrat A. (2018) Potential geoheritage sites in Ethiopia: challenges of their promotion and conservation. In: Reynard E., Brilha, J. (Eds) Geoheritage: assessment, protection, and management. Elsevier, Amsterdam, pp. 339-355. https://doi.org/10.1016/B978-0-12809531-7.00019-8

Asrat A, Demissie M, Mogessie A (2012) Geoheritage conservation in Ethiopia: the case of the Simien Mountains. Quaestiones Geographicae 31(7):23-23. https://doi.org/10.2478/v10117-0120001-0

Barberi F., Borsi S., Ferrara G., Martinelli G., Varet J. (1970) Relations between tectonics and magmatology in the northern Danakil Depression (Ethiopia). Philosophical Transactions of The Royal Society A Mathematical Physical and Engineering Sciences 267: 293-311. https://doi.org/10.1098/rsta.1970.0037

Bastow IA, Booth AD, Corti G, Kier D, Magee C, Jackson CAL, Warren J, Wilkinson J, Lascialfari M (2018) The development of late-stage continental breakup: seismic reflection and borehole evidence from the Danakil Depression, Ethiopia. Tectonics 37:2848-2862. https:// doi.org/10.1029/2017TC004798

Belilla J, Moreira D, Jardillier L, Reboul G, Benzerara K, López-García JM, Bertolino P, López-Archilla AI, López-García P (2019) Hyperdiverse archaea near life limits at the polyextreme geothermal Dallol area. Nature Ecology \& Evolution 3:1552-1561. https://doi. org/10.1038/s41559-019-1005-0

Brilha J (2016) Inventory and quantitative assessment of geosites and geodiversity sites: a review. Geoheritage 8(2):119-134. https://doi. org/10.1007/s12371-014-0139-3

Brilha J. (2018) Geoheritage: a multidisciplinary and applied research topic. In: Reynard E., Brilha J. (Eds) Geoheritage: assessment, protection, and management. Elsevier, Amsterdam. pp. 3-9. https://doi. org/10.1016/B978-0-12-809531-7.00030-7

Brocx M, Semeniuk V (2007) Geoheritage and conservation: history, definition, scope and scale. J R Soc West Aust 90:53-87

Burek C.V., Prosser C.D. (Eds.) (2008) The history of geoconservation. The Geological Society, London, Special Publication 300, 1, 5

Carniel R, Muñoz Jolis E, Jones E (2010) A geophysical multi-parametric analysis of hydrothermal activity at Dallol, Ethiopia. J Afr Earth Sci 58 (5):812-819. https://doi.org/10.1016/j.jafrearsci.2010.02.005

Cavalazzi B, Barbieri R, Gómez F, Capaccioni B, Olsson-Francis K, Pondrelli M, Rossi AP, Hickman-Lewis K, Agangi A, Gasparotto G, Glamoclija M, Ori GG, Rodriguez N, Hagos M (2019) The Dallol geothermal area, northern Afar (Ethiopia)-an exceptional planetary field analog on earth. Astrobiology 19(4):554-577. https://oi.org/10.1089/ast.2018.1926
Council of Ministers Regulations No. 163 (2008) Wildlife development, conservation and utilization. Council of Ministers of the Federal Democratic Republic of Ethiopia, $36 \mathrm{p}$

Cumbe A.N.F. (2007) O Património Geológico de Moçambique: Proposta de Metodologia de Inventariação/Caracterização e Exemplos de Aplicação. Tese de Mestrado em Património Geológico e Geoconservação (Master's thesis). Universidade do Minho, Braga, $273 \mathrm{pp}$

Dallol (2020) The volcanism of Dallol http://dallol.lmv.uca.fr/ (Accessed $01 / 04 / 2020)$

Darrah TH, Tedesco D, Tassi F, Vaselli O, Cuoco E, Poreda RJ (2013) Gas chemistry of the Dallol region of the Danakil Depression in the Afar region of the northern-most East African Rift. Chem Geol 339: 16-29. https://doi.org/10.1016/j.chemgeo.2012.10.036

Dingwall P, Weighell T, Badman T (2005) Geological world heritage: a global framework. A Contribution to the Global Theme Study of World Heritage Natural sites, IUCN, Gland, $51 \mathrm{p}$

Dudley N (ed) (2008) Guidelines for applying protected area management categories. IUCN, Gland, 86 pp. https://doi.org/10.2305/ IUCN.CH.2008.PAPS.2.en

Erfurt-Cooper P (2011) Geotourism in volcanic and geothermal environments: playing with fire? Geoheritage 3:187-193. https://doi.org/10. 1007/s12371-010-0025-6

ERM (2015) Final environmental and social impact assessment report for the Yara Dallol potash project. Environmental Resources Management Southern Africa (Pty) Ltd. (ERM), Ref: 0224244

Errami E., Ennih N., Bendaoud A., Bouzidi O., Chabou M.C., Andrianaivo L., Ben Ismail-Lattrache K., Hassine M. (2013) Inventaire du géopatrimoine en Afrique: état des lieux et perspectives. In Egoroff G., Cornée A., De Wever P., Lalanne A. (Eds.) (2013) Actes du colloque « Géopatrimoine, un lustre d'inventaire en France ».10-.12 octobre 2012, Digne-les-Bains. Mém. H.S. Société Géologique de France 13: 128-139

ETOA (2020): Ethiopian Tour Operators Association https:// ethiopiantourassociation.com/ (Accessed 01/04/2020)

Franzson H., Helgadóttir H. M., Óskarsson F. (2015) Surface exploration and first conceptual model of the Dallol Geothermal area, northern Afar, Ethiopia. Proceedings World Geothermal Congress 2015: 1-11

Gebresilassie S, Tsegab H, Kabeto K, Gebreyohannes T, Sewale A, Amare K, Mebrahtu A, Zerabruk S, Mebrahtu G, Gebrehiwot K, Haile M (2011) Preliminary study on geology, mineral potential and characteristics of hot springs from Dallol area, Afar rift, northeastern Ethiopia: implications for natural resource exploration. Momona Ethiop J Sci 3:1-14. https://doi.org/10.4314/mejs.v3i2.67710

GGN (2012) The Shimbara declaration. Unzen Volcanic Area Global Geopark. Global Geoparks Network https://geopark.jp/about/pdf/ geoparks2012 en.pdf. (Accessed 11/10/2019)

GGN (2020) Global Geoparks Network http://www.globalgeopark.org/ (Accessed 01/04/2020)

Giardino M., Lombardo V., Lozar F., Magagna A., Perotti L. (2014) GeoMedia-web: multimedia and networks for dissemination of knowledge on geoheritage and natural risk. In: Lollino G., Arattano M., Giardino M., Oliveira R., Peppoloni S. (eds) Engineering geology for society and territory. Springer, Cham. 7: 147-150. https://doi.org/10.1007/978-3-319-09303-1_28

Gizzi FT, Bentivenga M, Lasaponara R, Danese M, Potenza MR, Sileo M, Masini N (2019) Natural hazards, human factors, and "ghost towns": a multi-level approach. Geoheritage, pp 11:1-33. https:// doi.org/10.1007/s12371-019-00377-y

Gómez F, Cavalazzi B, Rodríguez N, Amils R, Ori GG, Olsson-Francis K, Escudero C, Martínez JM, Hagos M (2019) Ultra-small microorganisms in the polyextreme conditions of the Dallol volcano, Northern Afar, Ethiopia. Sci Rep 9(1):1-9. https://doi.org/10.1038/ s41598-019-44440-8 
Goudie A.S. (1989) Salt tectonics and geomorphology. Progress in Physical Geography: Earth and Environment, 13(4): 597-605. https://doi.org/10.1177/030913338901300405

Hagos M., Bheemalingeswara K., Ahmed J. (2016) A preliminary Geological and Generalized Stratigraphy of Western Margin of Northern Afar Depression, Dallol Area, Northern Ethiopia. Momona Ethiop J Sci 8. https://doi.org/10.4314/mejs.v8i1.1

Hagos M, Koeberl C, Jourdan F (2017) Geochemistry and geochronology of phonolitic and trachytic source rocks of the Axum Obelisks and other stone artifacts, Axum, Ethiopia. Geoheritage 9:479-494. https://doi.org/10.1007/s12371-016-0199-7

Holwerda JG, Hutchinson RW (1968) Potash-bearing evaporites in the Danakil area, Ethiopia. Econ Geol 63(2):124-150. https://doi.org/ 10.2113/gsecongeo.63.2.124

IUCN (2000) A guide to the assessment of biological diversity: draft. IUCN M\&E Initiative, IUCN Biodiversity Policy and International Agreements Unit http://cmsdata.iucn.org/downloads/ biodiversity_ assessment_guide.pdf (Accessed 11/10/2019)

Jones C (2008) History of Geoparks. In: Burek C.V., Prosser C.D. (Eds.) (2008) The history of geoconservation. The Geological Society, London, Special Publication 300, pp. 273-277

Joyce B (2009) Geomorphosites and volcanism. In: Reynard E, Coratza P, Regolini-Bissig G (eds) Geomorphosites. Verlag Dr. Friedrich Pfeil, Munich, Germany, pp 175-188

López-García JM, Moreira D, Benzerara K, Grunewald O, López-García P (2020) Origin and evolution of the halo-volcanic complex of Dallol: proto-volcanism in Northern Afar (Ethiopia). Front Earth Sci 7:351. https://doi.org/10.3389/feart.2019.00351

Lupi L (2009) L'Esplorazione della Dancalia. La contesa per el primato. Bolletino della Societa Goeografica Italiana 13(2):827-875

Macadam J. (2018) Geoheritage: getting the message across. What message and to whom. In: Reynard E., Brilha J. (Eds) Geoheritage: assessment, protection, and management. Elsevier, Amsterdam, pp. 267-289. https://doi.org/10.1016/B978-0-12-809531-7.00015-0

Makris J, Ginzburg A (1987) The Afar Depression: transition between continental rifting and sea-floor spreading. Tectonophysics 141(13):199-214. https://doi.org/10.1016/0040-1951(87)90186-7

Mauerhofer L, Reynard E, Asrat A, Hurni H (2017) Contribution of a geomorphosite inventory to the geoheritage knowledge in developing countries: the case of the Simien Mountains National Park. Ethiopia Geoheritage 10:559-574. https://doi.org/10.1007/s12371017-0234-3

McNutt S. R. (1996) Seismic monitoring and eruption forecasting of volcanoes: a review of the state of the art and case histories. In: Scarpa \& Tilling (Eds), Monitoring and mitigation of volcano hazards. Springer, Berlin-Heidelberg. pp. 99-146

Megerssa L, Rapprich V, Novotný R, Verner K, Erban V, Legesse F, Manaye M (2019) Inventory of key geosites in the Butajira volcanic field: perspective for the first geopark in Ethiopia. Geoheritage 2019:1-11. https://doi.org/10.1007/s12371-019-00393-y

Moufti MR, Németh K, El-Masry N, Qaddah A (2015) Volcanic geotopes and their geosites preserved in an arid climate related to landscape and climate changes since the neogene in Northern Saudi Arabia: Harrat Hutaymah (Hai'il region). Geoheritage 7:103-118. https://doi.org/10.1007/s12371-014-0110-3

Nakada S (2018) Volcanic archipelago: volcanism as a geoheritage characteristic of Japan. In: Chakraborty A, Mokudai K, Cooper M, Watanabe M, Chakraborty K (eds) Natural heritage of Japan. Geoparks and Geotourism. Springer, Geoheritage, pp 19-28. https://doi.org/10.1007/978-3-319-61896-8 3

Ngwira MP (2015) Geotourism and geoparks: Africa's current prospects for sustainable rural development and poverty alleviation. In: Errami E, Brocx M, Semeniuk V (eds) From geoheritage to geoparks: case studies from Africa and beyond. Springer, Heidelberg, pp 25-33. https://doi.org/10.1007/978-3-319-10708-0_2
Nobile A, Pagli C, Keir D, Wright TJ, Ayele A, Ruch J, Acocella V (2012) Dike-fault interaction during the 2004 Dallol intrusion at the northern edge of the Erta Ale Ridge (Afar, Ethiopia). Geophys Res Lett 39:1-6. https://doi.org/10.1029/2012GL053152

Nyssen J, Jacob M, Frankl A (2019) Geo-trekking in Ethiopia's tropical mountains: the Dogu'a Tembien District. Springer, 675 pp. https:// doi.org/10.1007/978-3-030-04955-3

Planet Labs Inc. (2020) Planet.com - Planet Explorer https://www.planet. com/explorer/ (Accessed 01/04/2020)

Proclamation 541 (2007) Development conservation and utilization of wildlife proclamation. Federal Negarit Gazeta of the Federal Democratic Republic of Ethiopia 13(51): 3734-3745

QGIS Development Team (2020) QGIS geographic information system. Open Source Geospatial Foundation. http://qgis.org (Accessed 01/ 04/2020)

Ranke U (2016) Natural disaster risk management: geosciences and social responsibility. Springer International Publishing, Cham, 514 pp. https://doi.org/10.1007/978-3-319-20675-2

Renzulli A, Antonelli F, Margottini C, Santi P, Fratini F (2011) What kind of volcanite the rock-hewn churches of the Lalibela UNESCO's world heritage site are made of? J Cult Herit 12(2): 227-235. https://doi.org/10.1016/j.culher.2010.11.003

Reynard E., Brilha J. (Eds) (2018) Geoheritage: assessment, protection, and management. Elsevier, Amsterdam, 484 pp, Geoheritage.

Reynard E., Fontana G., Kozlik L., Scapozza C. (2007) A method for assessing "scientific" and "additional values" of geomorphosites. Geographica Helvetica 62 (3): 148158

Reynard E, Perret A, Bussard J, Grangier L, Martin S (2016) Integrated approach for the inventory and management of geomorphological heritage at the regional scale. Geoheritage 8(1):43-60. https://doi. org/10.1007/s12371-015-0153-0

Rogers N.W. (2006) Basaltic magmatism and the geodynamics of the East African Rift System. Geological Society of London Special Publications 259: 77-93. https://doi.org/10.1144/GSL.SP.2006. 259.01.08

Scaini C, Felpetob A, Martí J, Carniel R (2014) A GIS-based methodology for the estimation of potential volcanic damage and its application to Tenerife Island, Spain. J Volcanol Geotherm Res 278-279: 40-58. https://doi.org/10.1016/j.jvolgeores.2014.04.005

Schneider G.I.C., Schneider M.B. (2005) Gondwanaland Geopark - a proposed Geopark for Namibia 87 pp- http://portal.unesco.org/en/ files/47468/12665840421Gondwana_Park_sm.pdf/Gondwana\% 2BPark\%2Bsm.pdf (Accessed 11/10/2019)

Sparks RSJ, Biggs J, Neuberg JW (2012) Monitoring volcanoes. Science 335(6074):1310-1311. https://doi.org/10.1126/science.1219485

Szepesi J, Sz H, Zs É, Novák TJ, Lukács R, Soós I (2017) Volcanic geoheritage and geotourism perspectives in Hungary: a case of an UNESCO world heritage site, Tokaj wine region historic cultural landscape, Hungary. Geoheritage 9:329-349. https://doi.org/10. 1007/s12371-016-0205-0

Tazieff H, Varet J, Barberi F, Giglia G (1972) Tectonic significance of the Afar (or Danakil) Depression. Nature 235:144-147. https://doi.org/ 10.1038/235144a0

Tessema ME, Lilieholm RJ, Ashenafi ZT, Leader-Williams N (2010) Community attitudes toward wildlife and protected areas in Ethiopia. Soc Nat Resour 23(6):489-506. https://doi.org/10.1080/ 08941920903177867

Thomas M., Asrat A. (2018) The potential contribution of geotourism in Africa. In: Dowling R., Newsome D. Handbook of geotourism, Edward Elgar, pp. 520

Tibaldi A., Bonali F.L., Vitello F., Delage E., Nomikou P., Antoniou V., Becciani U., van Wyk de Vries B., Krokos M., Whitworth M. (2020) Real world-based immersive Virtual Reality for research, teaching and communication in volcanology. Bulletin of Volcanology 82:38. https://doi.org/10.1007/s00445-020-01376-6 
Tomić N, Božić S (2014) A modified geosite assessment model (MGAM) and its application on the Lazar Canyon area (Serbia). Int J Environ Res 8(4):1041-1052

UNESCO-IGGP (2015). Statutes of the International Geosciences and Geoparks Programme. https://unesdoc.unesco.org/ark:/48223/ pf0000260675.page $=4$ (Accessed 11/10/2019)

UNISDR (2009) 2009 UNISDR terminology on disaster risk reduction. https://www.unisdr.org/we/inform/publications/7817 (Accessed 11/ 10/2019)

Vereb V., van Wyk de Vries, B., Hagots, M. (2019) Remote sensing monitoring and geosite assessment of Dallol, Ethiopia. Putting an isolated and deserted area on map with geoheritage and resilience. Geophysical Research Abstracts 21 Paper: EGU2019-5640

Vreugdenhil D, Vreugdenhil AM, Tilahun T, Shimelis A, Tefera Z (2012) Gap analysis of the protected areas system of Ethiopia. World Institute for Conservation and Environment - Ethiopian Wildlife Conservation Authority, Addis-Ababa, pp 1-68

Vujičić MD, Vasiljević DA, Marković SB, Hose TA, Lukić T, Hadžić O, Janićević S (2011) Preliminary geosite assessment model (GAM) and its application on Fruška gora mountain, potential geotourism destination of Serbia. Acta Geographica Slovenica 51(2):361-377. https://doi.org/10.3986/AGS51303

Warren J. K. (2015a) Danakhil potash, Ethiopia: is the present geology the key? Part 1 of 4. Salty Matters: 1-10. https://doi.org/10.13140/ RG.2.1.4752.2728

Warren J. K. (2015b) Danakhil potash, Ethiopia: beds of kainite/carnallite. Part 2 of 4. Salty Matters: 1-7 https://doi.org/10.13140/RG.2.1. 2392.9769

WDPA (2020) World database on protected areas https://www. protectedplanet.net/ (Accessed 01/04/2020)

WHC (2017) Operational Guidelines for the Implementation of the World Heritage Convention https://whc.unesco.org/en/guidelines/ (Accessed 11/10/2019)

Williams FM (2016) Understanding Ethiopia: geology and scenery. Springer, Cham, 343 pp. https://doi.org/10.1007/978-3-31902180-5

Zouros N. (2004) The European geoparks network. Geological heritage protection and local development. Episodes 27: 165-171. https:// doi.org/10.18814/epiiugs/2004/v27i3/002 